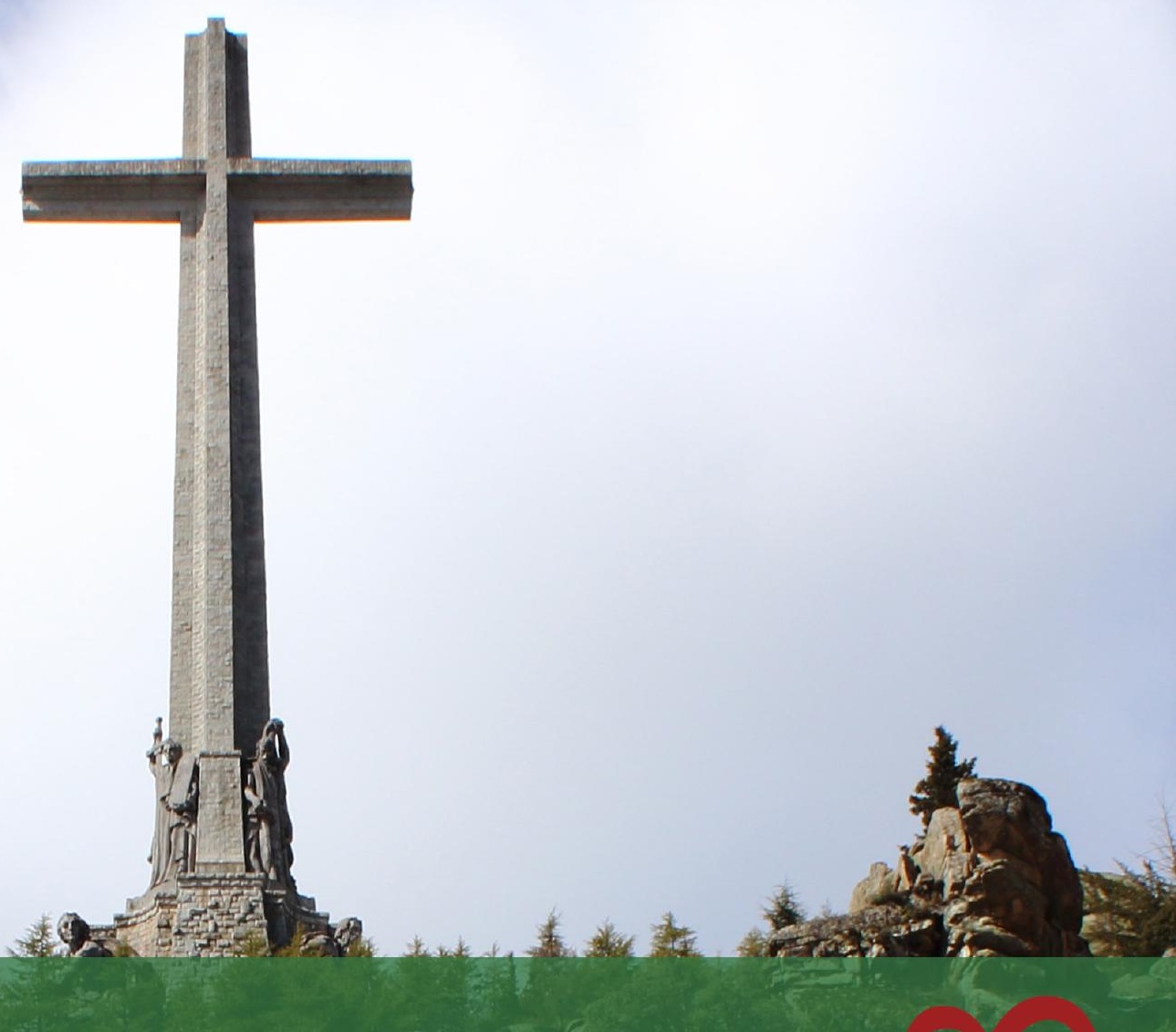

Revista digital de Ciencia y Didáctica de la Historia

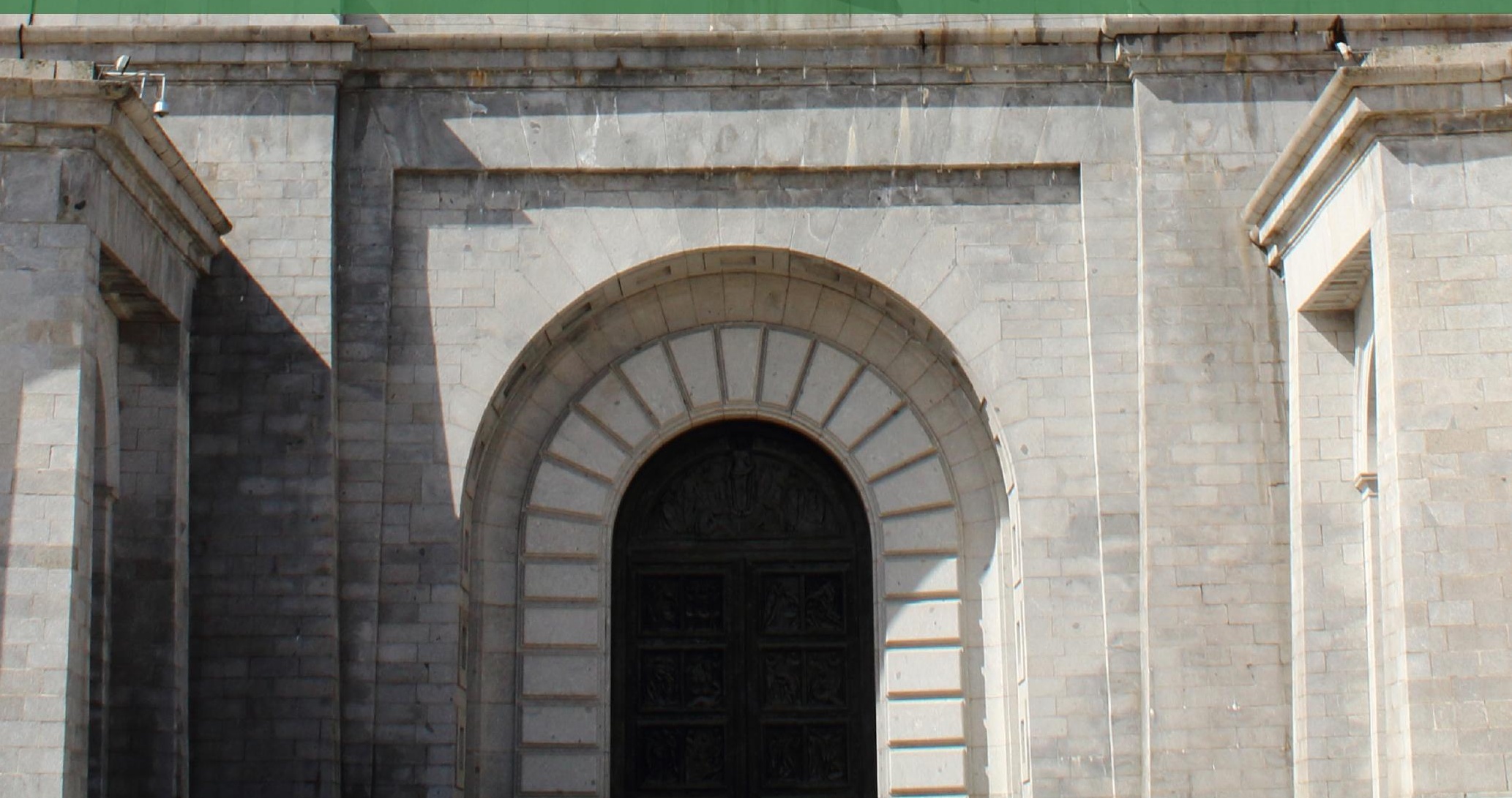




\section{Panta Rei \\ Revista Digital de Ciencia \\ y Didáctica de la Historia}

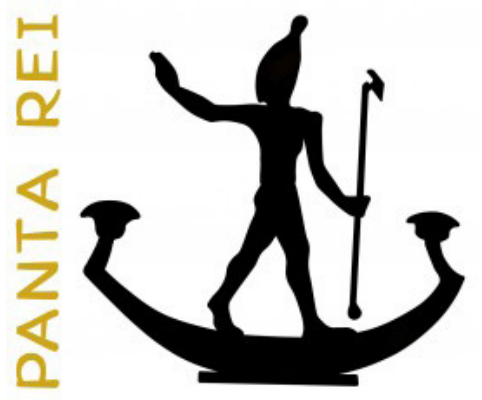

\section{8}

Revista anual

Fecha de inicio: 1995

Revista Panta Rei. pantarei@um.es

Edita:

Centro de Estudios del Próximo Oriente y la Antigüedad Tardía - CEPOAT

Edificio Universitario Saavedra Fajardo.

Universidad de Murcia

C/ Actor Isidoro Máiquez, 9

30007 - MURCIA - ESPAÑA

Teléfono: (+34) 868883890

cepoat@um.es

Web: www.um.es/cepoat/pantarei

Edición 2018

ISSNe: 2386-8864

ISSN: 1136-2464

Depósito legal: MU-966-1995

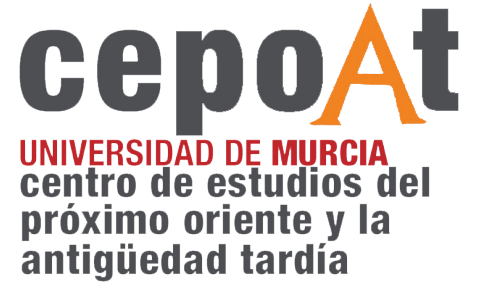

En Portada: Valle de los Caídos, Madrid. (Fotografía de: Adrián Rosell Lucas).

Responsables de los textos: Sus autores.

Responsable de la presente edición: Consejo Editorial Panta Rei. 


\section{CONSEJO DE REDACCIÓN}

\section{Coordinador editorial}

Egea Vivancos, Alejandro

[Didáctica de las Ciencias Sociales, UMU]

\section{Editores}

Botí Hernández, Juan Jesús

[CEPOAT, UMU]

Jiménez Vialás, Helena

[UMU]

López Muñoz, Damaris

[UJA]

Meseguer Gil, Antonio José

[CEPOAT, UNED]

Sáez Giménez, David Omar

[CEPOAT, UMU]

Sánchez Mondéjar, Celso Miguel

[Patrimonio Inteligente]

\section{Secretaria}

Arias Ferrer, Laura

[Didáctica de las Ciencias Sociales, UMU]

\section{Responsable informático}

Martínez García, José Javier

[CEPOAT, UMU]

\section{Traducción y corrección lingüística}

Martínez Martínez, Cristina

[Sociedad Española de Lenguas Modernas]

Albaladejo Albaladejo, Sara

[ISEN, UMU]

\section{CONSEJO ASESOR}

Adroher Auroux, Andrés María [Arqueología, Universidad de Granada]

Albero Muñoz, $\mathrm{M}^{\mathrm{a}}$ del Mar $\left[\mathrm{H} .^{\mathrm{a}}\right.$ del Arte, Universidad de Murcia]

Alia Miranda, Francisco [Historia Contemporánea, UCLM]

Arciniega García, Luis [Historia del Arte, Universidad de Valencia]
Barrio Barrio, Juan Antonio [Historia Medieval, Universidad de Alicante]

Castellano i Solé, Núria [Egiptología, Schola Didàctica Activa S.L.]

Chapman, Arthur [History Education, University College of London, Reino Unido]

Cid López, Rosa María [Historia Antigua, Universidad de Oviedo]

Cobacho López, Ángel [Derecho, Universidad de Murcia]

Cuenca López, José María [Didáctica de las Ciencias Sociales, Universidad de Huelva]

Egea Bruno, Pedro $\mathrm{M}^{\mathrm{a}}$ [Historia Contemporánea, Universidad de Murcia]

Feijoo Martínez, Santiago [Arqueología, Consorcio Ciudad Monumental de Mérida]

García Atienzar, Gabriel [Prehistoria, Universidad de Alicante]

Ginestí Rosell, Anna [Filología Clásica, Katholische Universität Eichstätt-Ingolstadt]

González Monfort, Neus [Didáctica de las Ciencias Sociales, Universidad Autónoma de Barcelona]

González Soutelo, Silvia [Arqueología, Universidad de Vigo]

Haber Uriarte, María [Prehistoria, Universidad de Murcia]

Hernández de la Fuente, David [Historia Antigua, Universidad Complutense]

Hutson, Scott R. [Anthropology, University of Kentucky, EEUU]

Igual Luis, David [Historia Medieval, UCLM]

Irigoyen López, Antonio [Historia Moderna, Universidad de Murcia]

Jover Maestre, Francisco Javier [Prehistoria, Universidad de Alicante]

Mahony, Simon [Digital Humanities, University College of London, Reino Unido]

Marsilla de Pascual, Francisco Reyes [Técnicas historiográficas, Universidad de Murcia]

Martínez-Burgos García, Palma [H. ${ }^{\text {a }}$ del Arte, UCLM]

Mathis, Christian [Didaktik der Geschichte, PH Zürich]

Miralles Maldonado, José Carlos [Filología Clásica, Universidad de Murcia]

Molina Gómez, José Antonio [Historia Antigua, Universidad de Murcia]

Mónica Ghirardi [Historia Moderna, Universidad Nacional de Córdoba, Argentina]

Navarro Espinach, Germán [Historia Medieval, Universidad de Zaragoza]

Noguera Celdrán, José Miguel [Arqueología, Universidad de Murcia]

Ortiz Heras, Manuel [Historia Contemporánea, UCLM]

Panzram, Sabine [Historia Antigua, Universität Hamburg]

Pérez Molina, Miguel Emilio [Filología Clásica, Universidad de Murcia]

Prados Martínez, Fernando [Arqueología, Universidad de Alicante]

Sánchez Ibáñez, Raquel [Didáctica de las Ciencias Sociales, Universidad de Murcia]

Sancho Gómez, Miguel Pablo [Educación, UCAM]

Victoria Moreno, Diego [Historia Contemporánea, UNED]

Vilar García, María José [Historia Contemporánea, Universidad de Murcia]

Vivas Sainz, Inmaculada [H. ${ }^{\text {a }}$ del Arte, UNED]

Zamora López, José Ángel [Próximo Oriente Antiguo, CCHS-CSIC] 

Artículos

El estilo decorativo en las primeras producciones cerámicas en el valle del río Vinalopó (Alicante).

Silvia Martínez Amorós.

Límites históricos del Ateísmo: increencia en la Grecia Antigua.

Ramón Soneira Martínez. .33

Dynamics of Power: an Architectural Reading of the Concentration of Power (Ullastret, 4th-3rd Century BC).

David Jesús Cebrián Martínez.

La mujer como exemplum. Subversión, desafío y resistencia en Valerio Máximo.

Lidia González Estrada.

The narrative framing of violence in teaching resources about the Spanish Conquest of America.

Ángela Bermúdez Vélez y Diego Argumero Martínez.

Modelos de conciencia histórica en el alumnado de Educación Secundaria: tradición, simbología y contextualización en torno a los restos del franquismo.

Diego Miguel-Revilla y María Sánchez Agustí.

La importancia de la contextualización curricular en la enseñanza de la Historia en México.

Enrique Bautista Rojas.

Experiencia didáctica para la enseñanza de la historia contemporánea a través de las fuentes en Educación Superior.

Nayra Llonch-Molina y Verónica Parisi-Moreno 161

\section{Reseñas}

Prados, F., Jiménez, H., Martínez, J.J. (Eds.) (2017). Menorca entre fenicis i púnics / Menorca entre fenicios y púnicos. Murcia: Centro de Estudios del Próximo Oriente y la Antigüedad Tardía de la Universidad de Murcia. 320 págs.

Pete Missingham

Bravo Bosch, M. J. (2017). Mujeres y símbolos en la Roma Republicana. Análisis jurídico-histórico de Lucrecia y Cornelia. Madrid: Dykinson. 333 págs.

Borja Méndez Santiago.

Karp, M. (2016). This Vast Southern Empire: Slaveholders at the Helm of American Foreign Policy. Cambridge: Harvard University Press. 360 pages.

Kevin Caprice.

Livi-Bacci, Massimo (2012). A Short History of Migration. Cambridge: Polity Press. 157 pages.

Alejandro Salamanca Rodríguez. 189

Normas de publicación/Publishing rules 



\title{
El estilo decorativo en las primeras producciones cerámicas en el valle del río Vinalopó (Alicante)
}

\author{
Decorative Style in Early Pottery Production of the Valley of Vinalopó river (Alicante) \\ Martínez Amorós, Silvia ${ }^{1}$ \\ Universidad de Alicante
}

Recibido: 09/03/2017

Aceptado: $27 / 04 / 2018$

Para citar este artículo: Martínez Amorós, S. (2018). El estilo decorativo en las primeras producciones cerámicas en el valle del río Vinalopó (Alicante). Panta Rei. Revista Digital de Ciencia y Didáctica de la Historia, 9-32.

ISSNe: 2386-8864

DOI: $10.6018 /$ pantarei/2018/1

\begin{abstract}
Resumen
En el presente trabajo se aborda el estudio de seis vasos procedentes de yacimientos del valle del Vinalopó -Cueva Santa, Arenal de la Virgen, Ledua, La Alcudia y Cova de les Aranyes-, cronológicamente vinculados al Neolítico inicial. El estudio consiste en un análisis estilístico de los recipientes con el fin de definir su estilo decorativo. Se desarrolla también su comparación con las producciones cerámicas de las primeras comunidades neolíticas del valle del Serpis para así plantear la existencia o no de una barrera social entre estos dos espacios.
\end{abstract}

\section{Palabras clave}

Arqueología, arte, yacimientos, cultura, estudio comparativo, Neolítico Antiguo.

\section{Abstract}

In the present dissertation we study the Neolithic ceramic decorative style from the Vinalopó's Valley and from the Early Neolithic chronology, based on a sample of six ceramic vases - from Cueva Santa, Arenal de la Virgen, Ledua, Alcudia and Cova de les Aranyes -. The study consists of a ceramic stylistic analysis which attempts to define their decorative style. It has also been compared with the ceramic productions of the first Neolithic communities of the Serpis valley in order to question the existence or absence of a social barrier between these two areas.

\section{Keywords}

Archaeology, art, historic sites, culture, comparative study, Early Neolithic.

1 Para contactar con la autora: Silvia Martínez Amorós. Universidad de Alicante. silvia.24ma@gmail.com. 


\section{Introducción}

El presente trabajo pretende desarrollar un estudio centrado en el análisis de la cultura material del Neolítico inicial como indicador cultural, más concretamente en el estilo decorativo de las primeras cerámicas en el Vinalopó, a través del análisis decorativo de seis vasos cerámicos procedentes de diferentes yacimientos: el Arenal de la Virgen (Villena), la Cova de les Aranyes del Carabassí (Santa Pola), Ledua (Novelda), La Alcudia (Elche), y la Cueva Santa (Caudete) (Figura 1).

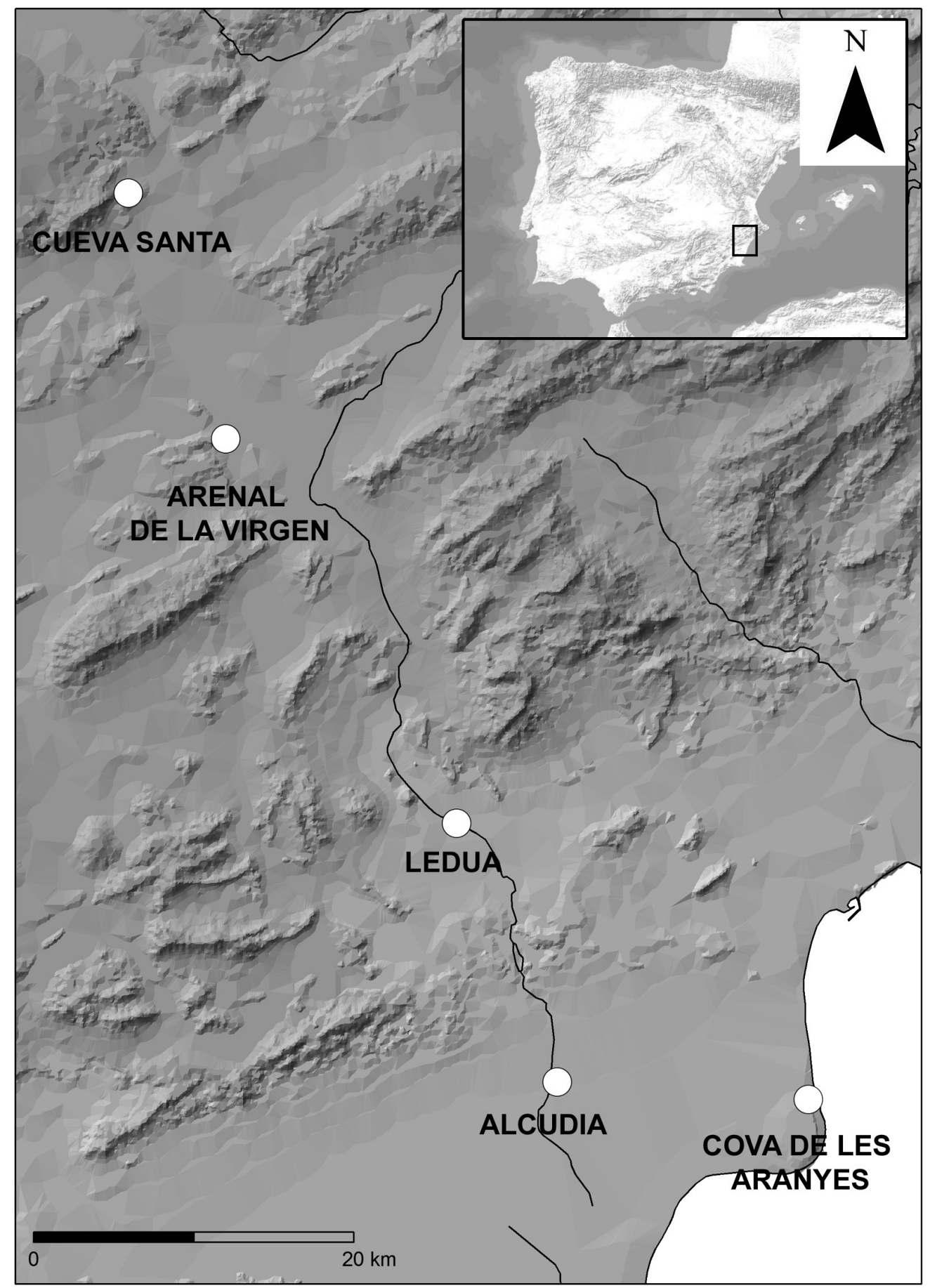

Figura 1: localización de los yacimientos. Fuente: elaboración propia. 
Tanto las formas como la tecnología o la decoración cerámica nos ofrecen información estilística que nos pueden ayudar a conocer los límites territoriales entre culturas, además de cuestiones relacionadas con las estructuras sociales, ideológicas y de poder. El método que emplearemos consiste en un análisis exhaustivo de la decoración cerámica basado en la descomposición de todos sus elementos, para así poder realizar una comparación entre ellos, pero también con otros conjuntos cerámicos del Neolítico valenciano. Por tanto, el objetivo final que se busca en este trabajo es establecer si las diferencias o semejanzas en el registro estilístico cerámico se corresponden con la existencia o no de una barrera social entre las comunidades neolíticas del valle del Vinalopó y las del valle del Serpis. Para reforzar los resultados obtenidos tras el estudio decorativo se ha añadido otro posible indicador cultural: el Arte Esquemático (AE) y Arte Macroesquemático (AM)2. Hay que aclarar que los resultados obtenidos no serán concluyentes, ya que la muestra analizada se limita a recipientes completos y no a todo el registro, pero sí que nos permitirán una primera aproximación, así como sentar las bases para futuros estudios.

\section{Marco teórico y metodología}

\subsection{Concepto de Estilo}

La cuestión del estilo puede ser de gran utilidad dentro del campo de la arqueología como herramienta para analizar, interpretar y comparar el registro material. Este concepto presenta algunas dificultades y es por esto que existe un gran número de publicaciones con el objetivo de definir sus características y posibles aplicaciones a los estudios arqueológicos (véase Sackett, 1977; Sterner, 1989; Wiessner, 1984; Wobst, 1977; Hegmon, 1992; Lemonnier, 1992; Dietler y Herbich, 1994, 1998; Hodder, 1977; Earle, 1990; Gosselain, 1992, etc.).

De forma sencilla, el estilo define los rasgos característicos que conforman las cualidades materiales de un objeto (material style), pero también nos referimos a estilo cuando hablamos de la forma de realizar cualquier acción (style of action) (Dietler y Herbich, 1998; Bernabeu, García, Gómez y Molina, 2011a). Pero además el estilo puede vincularse con el cambio cultural y social, a su vez, puede ser un reflejo directo del sistema socioeconómico en el que se inscribe, reflejar etnicidad, tener una función de intercambio de información, formar parte del sistema simbólico e ideológico de una sociedad, etc. (Prieto, 1998). Por otro lado, el estilo también puede informar de los límites territoriales entre culturas y de la existencia de interacción entre ellas (García Borja, 2015).

Aunque cualquier objeto puede reflejar estilo, la cerámica es considerada como uno de los principales depósitos de estilo ya que tradicionalmente se le ha asignado la capacidad de transmitir información social, ideológica y étnica (Sackett, 1977). Otro concepto relacionado con el estilo para la caracterización del registro cerámico es el de cadena operativa, que se entiende como el proceso físico de manufacturación de un objeto, prestando atención a la secuencia de gestos desempeñados para su producción, con la finalidad de describir los pasos para la fabricación de un tipo formal (Prieto, 1998). De esta forma, podemos decir que el estilo se encuentra presente en todos los procesos que afectan en la elaboración del recipiente cerámico: variabilidad tipológica, tecnológica y decorativa (García Borja, 2015).

\subsection{Metodología}

La metodología empleada es la definida por Bernabeu, García Borja, Gómez y Molina, (2011a) y aplicada en los trabajos de diversos yacimientos y colecciones: la Cova de les Cendres en Teulada, Alicante (Bernabeu y Molina, 2009), la Cueva de Nerja, en Maro, Málaga (García Borja, Aura, Bernabeu y Jordá, 2010), la Cova de l'Or en Beniarrés, Alicante (García Borja, Cortell, Pardo y

2 De aquí en adelante AE (Arte Esquemático) y AM (Arte Macroesquemático).

Panta Rei (2018), 9 - 32 
Pérez 2011) y la Cova de la Sarsa en Bocairent, Valencia (García Borja, 2016). El desarrollo de este sistema de trabajo se ha basado en modelos de referencia de la península como el estudio de Prieto (1999) para la cerámica Campaniforme en Galicia donde ésta se entiende como categoría de un estilo; o de otros ámbitos geográficos como los trabajos de Berg (1994) para el mundo del Rubané en Alsacia, o Manen (2002) para los contextos del Neolítico antiguo en el ámbito mediterráneo francés; y también se acerca a la propuesta del Sistema General Cerámico de Constantin (2000).

La metodología consiste en analizar desde la óptica del estilo la decoración cerámica mediante la descomposición de ésta a partir de diferentes grados de análisis, divididos en diferentes niveles de complejidad. Hay que entender que este proceso de descomposición de la decoración cerámica sigue un orden jerárquico, desde el nivel más alto que es el recipiente, al más bajo que es el gesto del artista. El nivel más alto está representado por el Tema decorativo, que a su vez está formado por Composiciones, elaboradas con diferentes Motivos, que están compuestos por los Elementos, todos estos realizados por la aplicación de una técnica decorativa (Bernabeu et al., 2011a).

Este método de trabajo para la descripción del estilo decorativo cerámico tiene unos códigos establecidas para su formulación, a partir de las cuales las descripciones se realizan de izquierda a derecha y de arriba hacia abajo. Además, cada elemento y cada regla (seriación, translación, orientación) cuenta con un código concreto dentro de un sistema alfanumérico, que mediante unas normas de formulación (Figura 2) se obtiene una fórmula que corresponde con la descripción de la decoración (Bernabeu et al., 2009).

Siguiendo la metodología (Bernabeu et al., 2009), la forma de representación gráfica también está establecida y reglada, y consiste en representar de forma esquematizada las decoraciones del vaso para facilitar la lectura. Se utilizarán para ello las mismas formas de representación de cada uno de los elementos reconocidos en el método, por tanto no se representa fielmente la decoración, sino que se trata de una idealización de la misma. Esta esquematización y simplificación en las representaciones permite una más fácil comparación y clasificación de la información. Se deben representar igualmente los elementos de suspensión, que aparecen con formas geométricas y rellenadas con tonos diferenciados.

/ Un motivo se encuentra sobre otro

$+\quad$ El siguiente motivo está a la derecha

- $\quad$ El motivo cubre o corta al siguiente

: $\quad$ Los motivos anteriores rodean de alguna manera a los siguientes

$<\quad$ Un motivo rellena el espacio definido por otro

A...n Los motivos sometidos a este signo se alteran

(...) Los motivos del interior tienen una relación particular que se desea aislar

[...] Todos los motivos del interior están afectados por el

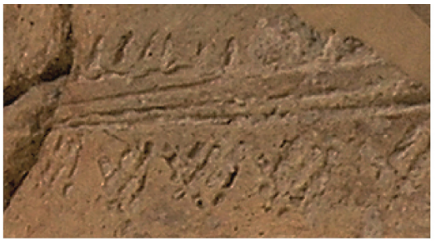

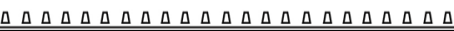
QW

signo que procede a los corchetes

$\{\ldots\} \quad$ Similar a los corchetes pero de mayor nivel
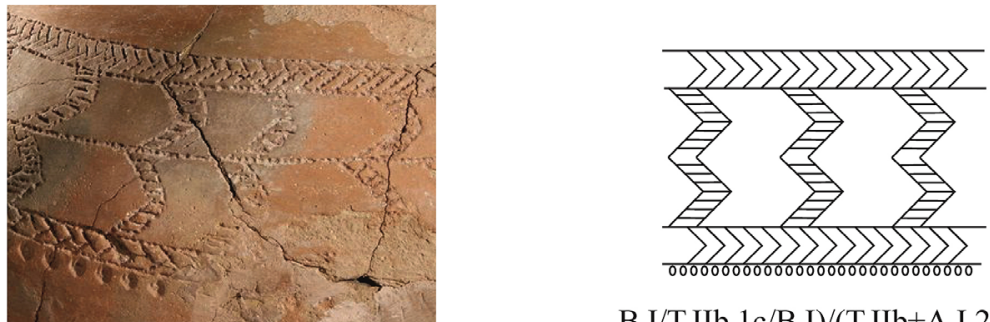

B.I/T.IIb.1c/B.I)/(T.IIb+A.I.2b+T.IIb)

$\mathrm{SHc} /$ B.I/(T.IIb+A.I.2b+T.IIb)SHc/E.IV.1c

Figura 2: reglas de adición entre motivos (según Bernabeu Aubán et al., 2011) y ejemplos de descripción de composiciones. Fuente: elaboración propia. 


\section{La implantación de las primeras comunidades agropecuarias en las comarcas centrales y meridionales valencianas}

El proceso de llegada de las primeras comunidades neolíticas a la península lbérica tuvo que realizarse por vía marítima, estas poblaciones se asentarían y penetrarían desde la desembocadura de los ríos, como el Serpis, hacia el interior del Prebético meridional valenciano, asentándose en las terrazas fluviales (García Atiénzar y Jover, 2014). Este proceso se ha estudiado a través de yacimientos como la Cova de l'Or (Beniarrés), la Cova de la Sarsa (Bocairent), la Cova de les Cendres (Teulada-Moraira), las prospecciones realizadas en diversas regiones del norte de Alicante (Bernabeu et al., 1989; Molina, 2003) y, más recientemente, a través de los resultados obtenidos en yacimientos al aire libre como Mas d'ls (Bernabeu et al., 2012) o Benàmer (Torregrosa et al., 2011). Este proceso se realizó en un tiempo relativamente corto, como confirman las dataciones y registro arqueológico disponibles. De este modo, hacia el 5600/5500 cal BC encontramos los primeros asentamientos de grupos neolíticos, conocidos como grupo cardial valenciano, en las cuencas de los ríos Serpis y Algar. Una vez implantados estos primeros grupos se inicia un proceso de crecimiento y consolidación demográfica y social de estas comunidades, de forma que hacia finales del VI cal milenio, una vez consolidadas las comunidades, se produciría la expansión y colonización de nuevas tierras colindantes (García Atiénzar y Jover, 2014).

En un primer momento, encontramos ocupaciones en las áreas endorreicas del corredor de Villena-Yecla, Foia de Castalla y zonas septentrionales del Camp d'Alacant, donde encontramos presencia de cerámicas cardiales junto con incisas, con relieves, con impresiones de instrumento y algunas peinadas, lo cual puede indicar una reocupación por grupos agropecuarios durante la fase de expansión y no ser resultado de un proceso de aculturación (García Atiénzar y Jover, 2014). En un segundo momento, encontramos asentamientos que al no constatar una presencia de cerámicas cardiales serían el resultado de una colonización posterior a la anterior. Este proceso de expansión y colonización de nuevas tierras se realizó siguiendo los corredores naturales que comunican la zona cardial con la Meseta y hacia el Sureste peninsular, siguiendo el Corredor del Vinalopó y el Corredor de Yecla/Jumilla donde encontramos como ejemplo de ello los yacimientos de la Cueva Santa de Caudete, Casa Lara y Arenal de la Virgen (Villena), la Cueva de cabezo de los Secos (Yecla) y la Cueva de los Tiestos (Jumilla). De esta forma, a inicios del V milenio cal BC ya se había realizado la colonización de las cuencas situadas al sur del territorio cardial, afectando a su vez a zonas más alejadas como la Vega del Segura y el nacimiento del río Mundo-Segura (Jover, Molina y García Atiénzar, 2008). Se produce también una expansión hacia el Sur-Sureste por el Corredor del Vinalopó hasta su desembocadura (Hernández, 1997). También desde la cabecera del Montnegre hacia el Camp d'Alacant y desde la cabecera del rio Penàguila a través del río de la Torre. Es a partir de los momentos centrales del $\mathrm{V}$ milenio cal BC cuando el proceso de consolidación, afianzamiento y aumento de población se iniciará en las tierras del Vinalopó, reflejándose en el aumento y distribución de los yacimientos en la cuenca del Vinalopó y también en la cuenca del Montnegre y Vega Baja del Segura (Jover et al., 2008).

\section{Descripción de los vasos cerámicos}

\subsection{El Alto Vinalopó: el Arenal de la Virgen, Villena y la Cueva Santa, Caudete}

En el Alto Vinalopó, la investigación de José María Soler García nos da las primeras referencias de poblados neolíticos (1961), pudiendo destacarse los hallazgos de Casa de Lara y Arenal de la Virgen. A estos asentamientos, vinculados, entre otras fases, al Neolítico Antiguo, pueden sumarse los hallazgos de la Cueva Santa de Caudete. 


\section{a) Arenal de la Virgen, Villena}

El Arenal de la Virgen se localiza en una amplia llanura al suroeste de la población, a las orillas de lo que fue la Laguna de Villena, a unos 490 M. S.n.m. Este yacimiento tradicionalmente se había asociado al proceso de neolitización, definiéndose como un asentamiento del epipaleolítico final con elementos materiales adoptados del Neolítico.

El yacimiento del Arenal de la Virgen fue descubierto por D. José María Soler en 1965. A mediados de los años 60, el Arenal de la Virgen y Casa Lara eran los primeros indicios de hábitat en llanura durante del Neolítico Antiguo, replanteando la denominada Cultura de las Cuevas definida por Bosch Gimpera en 1932 (Fernández, Gómez, Ferrer y YII, 2011). Las primeras intervenciones de José María Soler consistieron en la recuperación de los materiales superficiales en dos parcelas de viñedo. En el 2006 se reiniciaron los trabajos arqueológicos en el marco de un proyecto integral de revisión de las colecciones antiguas y de evaluación del potencial arqueosedimentario del yacimiento. En 2007 se realizó la segunda campaña de excavación, antes de la cual se efectuó una prospección con georradar en los sectores con mayor frecuencia de materiales líticos de superficie (Fernández et al., 2011). Actualmente se están realizado trabajos arqueológicos que están permitiendo delimitar espacialmente el área de distribución de las evidencias neolíticas, así como el estudio de los materiales cerámicos y del macroutillaje (Gómez y Fernández, 2016).

En cuanto a su cronología, la fase más antigua corresponde al Epipaleolítico de Muescas y Denticulados, prolongándose su ocupación hasta la fase A del Mesolítico Geométrico. El núcleo de la ocupación neolítica parece confinado a las dos parcelas plantadas con viñas en las que José María Soler efectuó sus prospecciones y parecen tener continuidad en los sectores más orientales de la parcela intervenida en 2006 y 2007. La ocupación neolítica aparece bien marcada por la presencia de cerámicas, además de los dos vasos con decoración impresa e incisa publicados en su momento por José María Soler (1965). Tanto por las técnicas decorativas como por la tipología de los materiales cerámicos podemos adscribir la ocupación neolítica a un momento del Neolítico inicial (NIA y NIB) (Gómez y Fernández, 2016). Entre los recipientes cerámicos destacan una olla globular de base convexa, una vasija globular con cuello, y otras formas simples. Según Fernández y otros (2011, p.104) "entre las técnicas decorativas predominan los cordones decorados y lisos, las decoraciones incisas/acanaladas y las impresas, con tres fragmentos con decoración cardial. Entre los hallazgos, también encontramos un conjunto de elementos de molienda relacionados presumiblemente con el procesado de cereales".
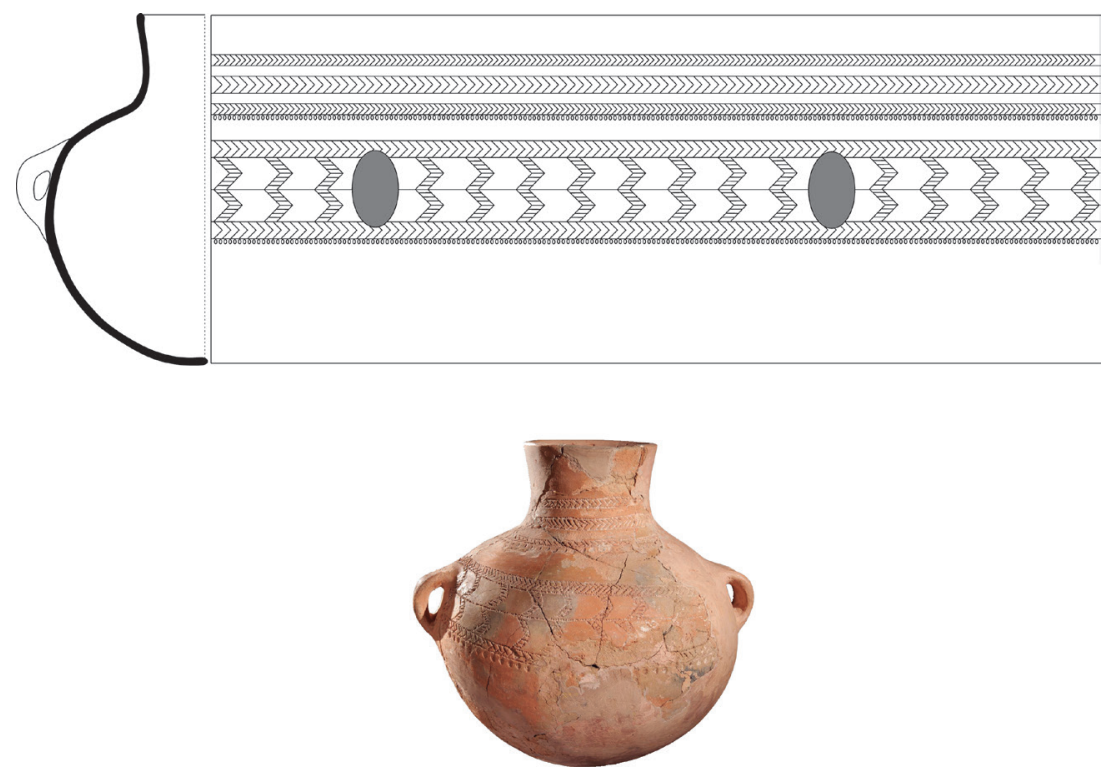

Figura 3: desarrollo de la composición decorativa del vaso I del Arenal de la Virgen. Fuente: elaboración propia a partir de fotografía del Museo Arqueológico "José María Soler" de Villena. 
Encontramos dos vasijas con decoración impresa. La primera de ellas presenta un cuerpo globular, cuello y dos asas de cinta vertical, con borde diferenciado recto-saliente y labio convexo. Presenta un tratamiento bruñido en el exterior de la superficie. La decoración aparece organizada en dos zonas en la parte superior del vaso. En el cuello, esta decoración está definida por bandas horizontales delimitadas por trazos paralelos y rellenas de un patrón de impresiones en forma de "V" realizadas con impresión de gradina. Debajo de esta composición vemos una línea de impresiones discontinuas realizadas con un instrumento de extremo redondeado. En la mitad del vaso, donde su ancho es mayor y donde están las asas, encontramos un motivo decorativo compuesto por dos bandas horizontales delimitadas por trazos paralelos y rellenas de un patrón de impresiones en forma de "V", que rodean a dos bandas formadas por motivos en "V" rellenos de incisiones, que dejan espacios sin decoración entre ellos de un tamaño superior a los rellenos. Por debajo de la composición, en paralelo, vuelve a aparecer una línea de impresiones discontinuas realizadas con un instrumento de punta redondeada.

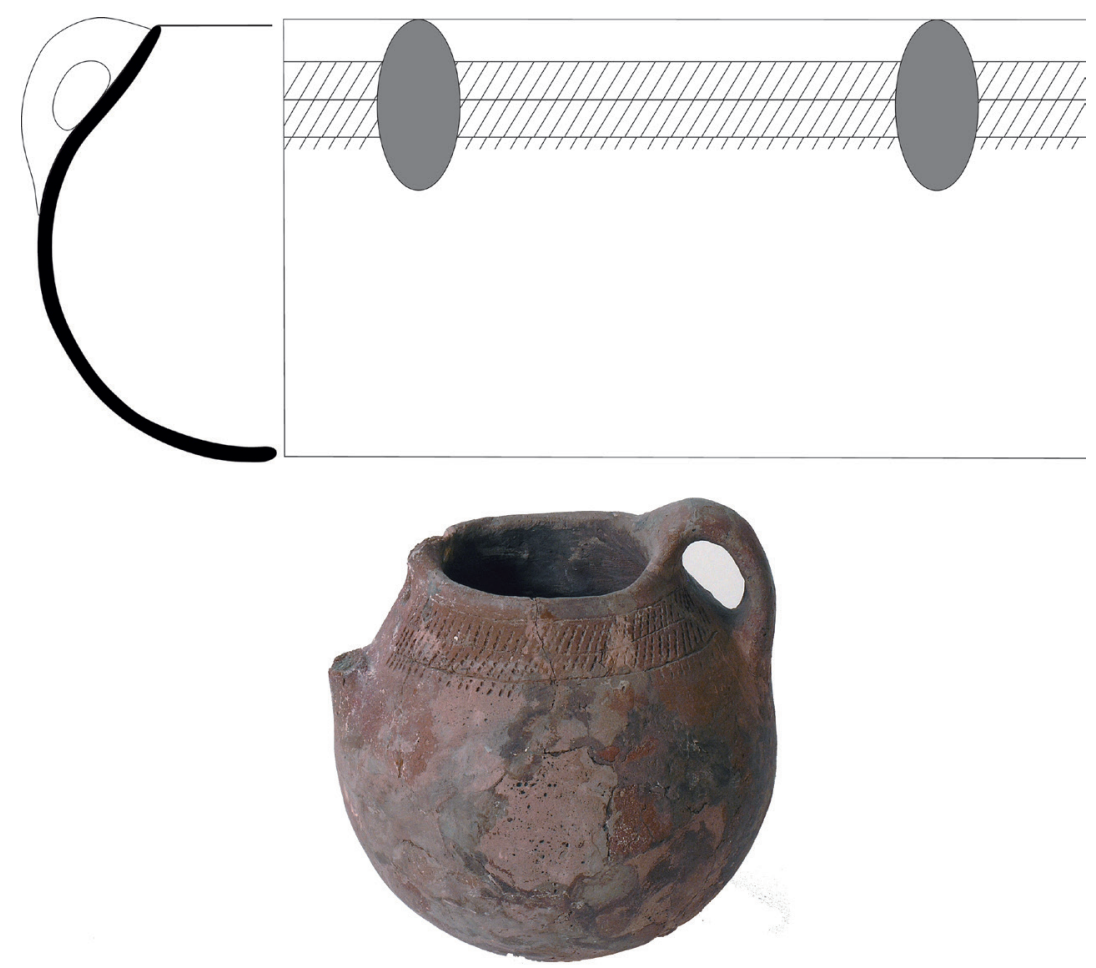

Figura 4: desarrollo de la composición decorativa del vaso II del Arenal de la Virgen. Fuente: elaboración propia a partir de fotografía del Museo Arqueológico “José María Soler" de Villena.

El segundo vaso es una olla globular de base convexa que presenta dos asas de cinta vertical, de las cuales sólo conserva una, que nacen del extremo superior del borde de la vasija. Presenta una única composición decorativa en el tercio superior, bordeando el cuello del vaso. Se trata de dos bandas horizontales delimitadas por trazos paralelos y rellenas por trazos oblicuos realizados mediante impresión con instrumento. Bajo la banda aparece una serie de trazos horizontales impresos más cortos (Gómez y Fernández, 2016).

\section{b) La Cueva Santa, Caudete}

Por otro lado, la Cueva Santa de Caudete se sitúa en la vertiente norte del cerro El Cinchado, a 800 M. S.n.m, cercana a la finca denominada "El Collado", en la localidad de Caudete, y en un lugar de tránsito que comunicaba la costa mediterránea con la Meseta meridional y Andalucía 
(Pérez, 1993).

Dado el estado de conservación de la cavidad a causa de la explotación como cantera, sólo quedan dos espacios en la sala de la entrada que no han sido destruidos. Una pequeña cavidad compuesta por un depósito de tierra marrón negruzco, donde se encontraron varios fragmentos de cerámica lisa pertenecientes al Neolítico y uno con decoración pintada de la cultura lbérica. En el fondo de la cavidad, en una pequeña grieta, se recogieron numerosos restos arqueológicos. Cuando comenzaron los trabajos de la cantera aparecieron diversos restos arqueológicos, entre ellos restos cerámicos, siendo el más importante el albergado por el Museo Arqueológico de Albacete, una vasija de tendencia esférica que conserva un asa de cinta horizontal con un pequeño mamelón a un lado. Cerca del labio tiene una pequeña sobreelevación horizontal a modo de cordón, y presenta decoración impresa cardial.

La dificultad de estudiar este yacimiento reside en que los materiales obtenidos son de superficie, y en que su estratigrafía ha sido remodelada alterando la situación original de los objetos, y dificultando así la cronología. Sin embargo, a partir de la cultura material recuperada durante los primeros trabajos de cantería, además de otros elementos conservados en otras instituciones museísticas (fragmentos con decoración impresa de gradina, digitaciones, etc.), se puede situar la cueva en el Neolítico Antiguo (VI-V milenio cal BC) (Pérez, 1993; García Atiénzar, 2010).
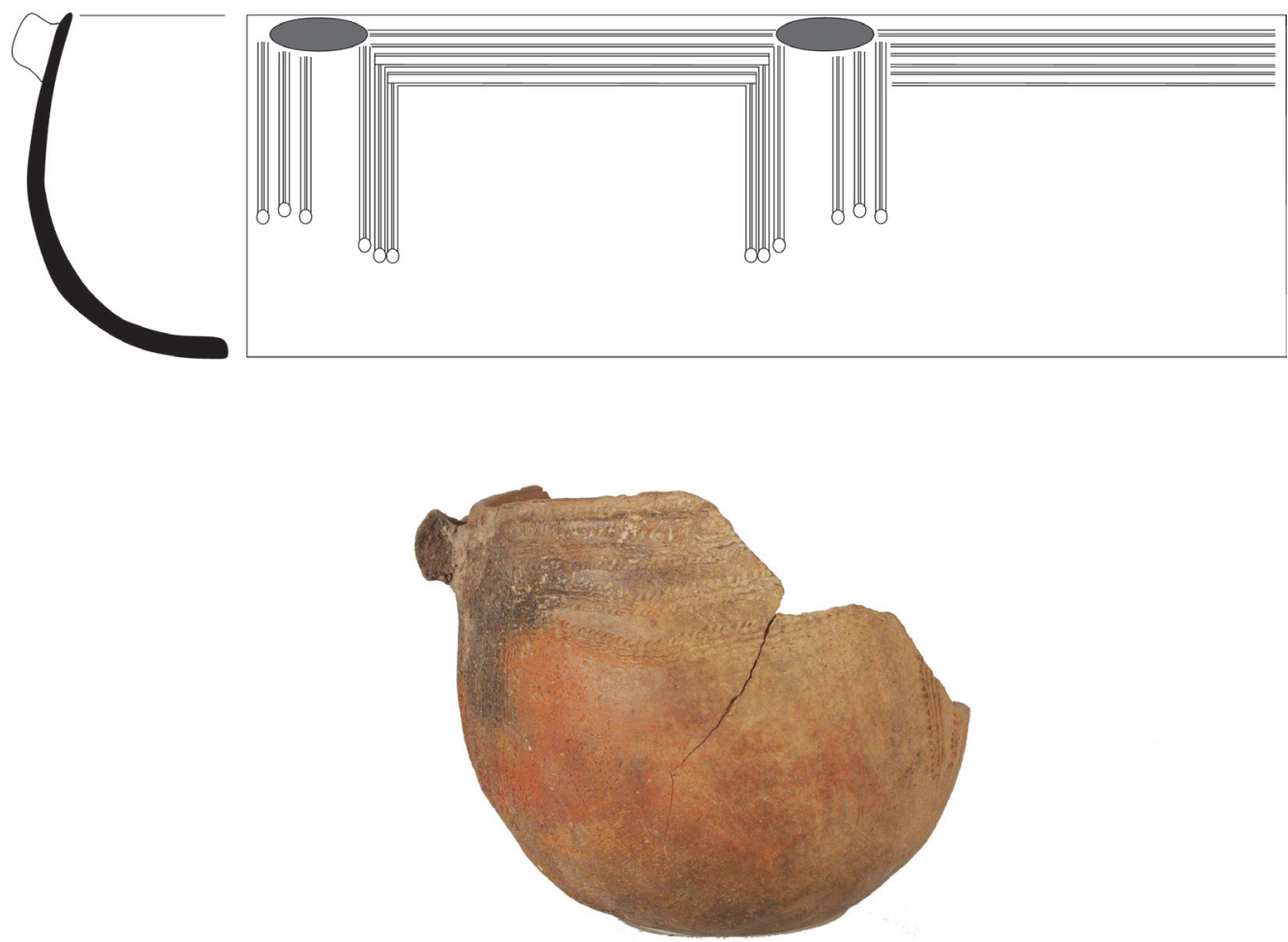

Figura 5: desarrollo de la composición decorativa del vaso de Cueva Santa, Caudete. Fuente: elaboración propia a partir de fotografía del Museo Provincial de Albacete.

En cuanto a la descripción de la cerámica estudiada en el presente trabajo, se trata de una vasija de cuerpo globular, sin base, que conserva un asa de cinta horizontal con un pequeño mamelón a un lado, cerca del labio tiene una pequeña sobreelevación horizontal a modo de cordón, presenta decoración impresa cardial formada por una serie de impresiones realizadas mediante la charnela y los bordes de Cardium edule, compuesta por la repetición de motivos de bandas, que se disponen de manera horizontal, y también vertical, rematados en el último caso por impresiones del umbo de la concha. 


\subsection{El Medio Vinalopó: Ledua, Novelda}

En el Medio Vinalopó, coincidiendo con el tramo central del Vinalopó, que está delimitado al norte por la Serra de l'Arguenya y la Sierra de la Umbría, y al sur por la Sierra de Crevillente y la Sierra del Tabayà, encontramos una importante concentración de yacimientos neolíticos, entre ellos el yacimiento de Ledua, en Novelda. Este yacimiento se ubica en la margen izquierda del río Vinalopó, en la Partida 59 del paraje.

A mediados de los ochenta, Elia Alberola tuvo noticias de la existencia de fragmentos cerámicos decorados lo que propició una campaña de excavación en 1987 dirigida por ella y M. S. Hernández. En los trabajos de excavación se practicaron cuatro cortes, tres de ellos elegidos por la presencia de tierras grises y piedra, y el Corte 4 por ser donde se encontraron fragmentos cerámicos. Es un yacimiento que se encontraba muy alterado por las actividades de arado, habiéndose perdido la totalidad de las estructuras de habitación. Pero sí se conservaban, en el Corte 2, una acumulación de piedras que podría ser los restos de muros, que serían cabañas frágiles, ligeramente rehundidas, o asociadas a silos (Hernández y Alberola, 1988).

Los restos materiales encontrados no son escasos, y destacan once láminas de sílex de pequeño tamaño, fragmentos de cerámica a mano, algunos decorados con incisiones e impresiones. El hallazgo más importante fue encontrado en el corte 4, tratándose de fragmentos que formaban parte de una vasija de cuerpo de tendencia esférica con cuello y asas verticales anulares decoradas por bandas horizontales incisas e impresas de triángulos rellenos (Hernández y Alberola, 1988: 155). A partir de dicho vaso se puede datar el yacimiento en momentos avanzados del Neolítico Antiguo, puesto que el vaso cerámico no presenta decoración cardial, fechada por tanto en los últimos siglos del VI milenio y los primeros del V.
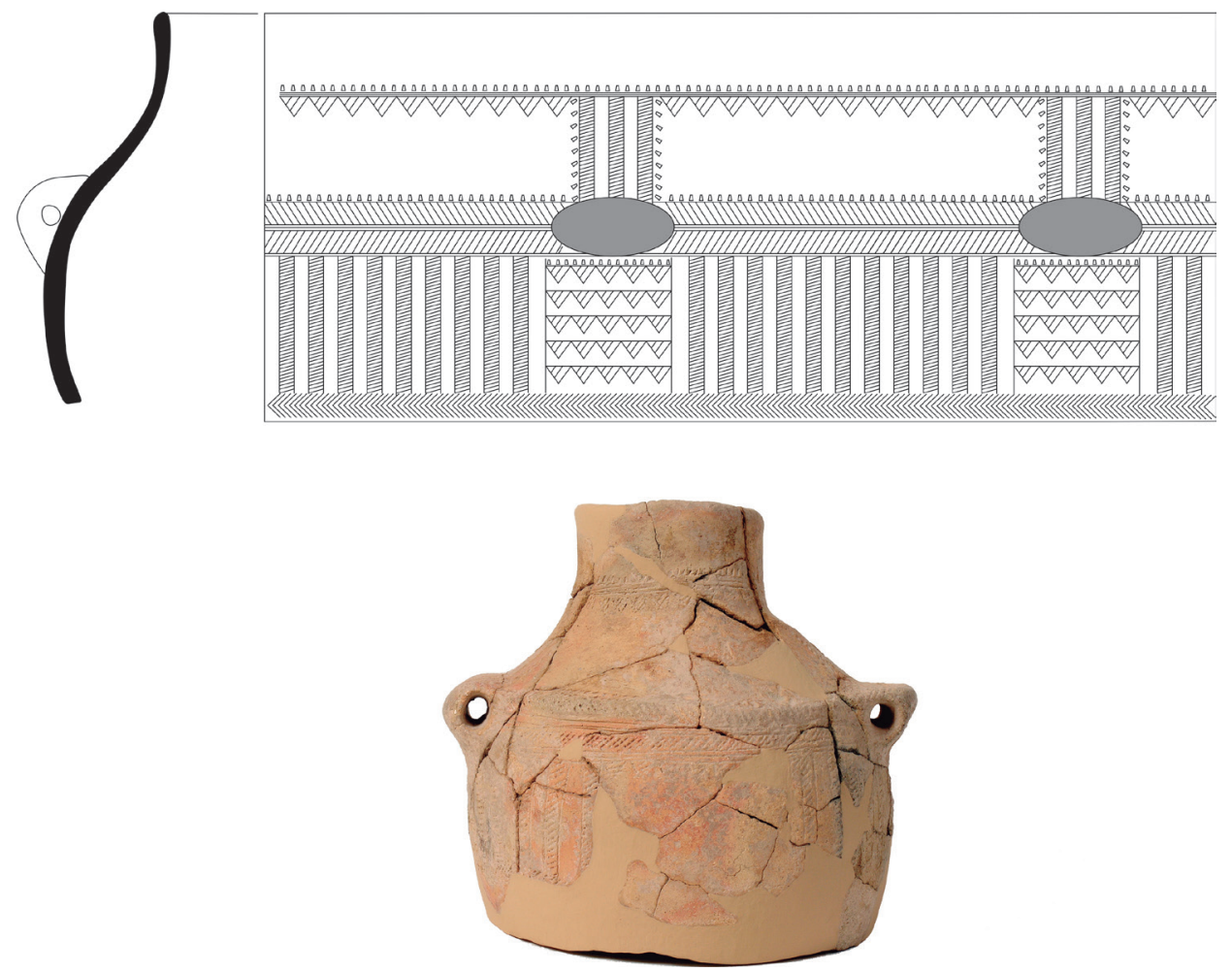

Figura 6: desarrollo de la composición decorativa del vaso cerámico de Ledua. Fuente: elaboración propia a partir de fotografía del Museo Arqueológico Municipal de Novelda. 
La vasija de tendencia esférica presenta cuello, borde ligeramente exvasado y extremo curvo con dos asas anulares verticales. La superficie externa se encuentra erosionada en algunos puntos y conserva en otros restos de engobe rojo. Su decoración está constituida, en la parte central del cuello, por bandas horizontales formadas por tres líneas incisas paralelas delimitadas en la parte superior por otras de impresiones discontinuas y en la inferior por triángulos rellenos de impresiones, que no rodean la totalidad del cuello al interrumpirse por varias bandas verticales de impresiones discontinuas dispuestas a modo de dos columnas delimitadas por incisiones y rellenas de impresiones y una incisión con impresiones discontinuas perpendiculares a uno de sus bordes. El hombro de la vasija, ligeramente engrosado, se decora en su parte superior con línea de impresiones discontinuas y en la inferior por una banda de impresiones de instrumento de tres puntas, separada por tres líneas incisas horizontales de otra similar, aunque en distinta orientación. Dos líneas incisas las delimitan por su parte baja, de la que arranca una decoración alternante de zonas lisas y columnas verticales formadas por dos líneas incisas rellenas de impresiones de instrumento de tres puntas. Esta decoración vertical alterna con otra constituida por líneas de triángulos invertidos, cuya base se adosa a líneas horizontales incisas, en dos de las cuales se marca en su parte superior otras líneas de impresión discontinuas. Esta misma asociación de líneas impresas e incisa se encuentra, asimismo, en uno de los lados que delimita este bloque decorativo, muestras en el otro sólo existe una incisión vertical. Cierra esta decoración en su parte inferior una barra vertical de impresiones de instrumento en espiga, que parece interrumpirse al alcanzar la zona decorada con triángulos (Hernández y Alberola, 1988: 155).

\subsection{El Bajo Vinalopó: La Alcudia y la Cova de les Aranyes del Carabassí}

El Bajo Vinalopó, comarca definida por la confluencia de las desembocaduras de los ríos Vinalopó y Segura, se caracteriza por un poblamiento neolítico importante que se documenta desde los inicios de la secuencia, con yacimientos en cavidades y también en torno a emplazamientos junto a los cauces de los ríos.

\section{a) La Alcudia}

Destacamos en primer lugar el yacimiento de La Alcudia, mejor conocido por sus ocupaciones posteriores, pero de donde también proceden restos prehistóricos. Se ubica en una colina natural, a unos $500 \mathrm{~m}$ del margen oeste del río Vinalopó y en el centro de una llanura deltaica con abundante agua.

Algunos de los materiales prehistóricos fueron descubiertos durante la excavación del sondeo 6-B del sector 5F de La Alcudia, donde se localizó una estructura subterránea de época moderna en cuyo interior aparecieron arenas relacionadas con la crecida del río asociadas a restos de fragmentos cerámicos (Ramos Folqués, 1989). Ramos Folqués (1989) sitúa otros hallazgos neolíticos al estrato $\mathrm{H}$. Destacan entre los materiales encontrados la presencia de fragmentos cerámicos con decoración impresa e incisa, siendo el más importante un vaso de forma globular con cuello, seis lengüetas y decoración geométrica en la que se combinan las técnicas de la incisión y la impresión de instrumentos (Ramos Molina, 1989). También encontramos puntas de flecha, lamitas retocadas, y fragmentos cerámicos a mano, fechados en momentos finales del Neolítico. La importancia de este yacimiento, al igual que Ledua o los ya nombrados yacimientos de Villena, reside en su carácter de asentamiento en llanura. 

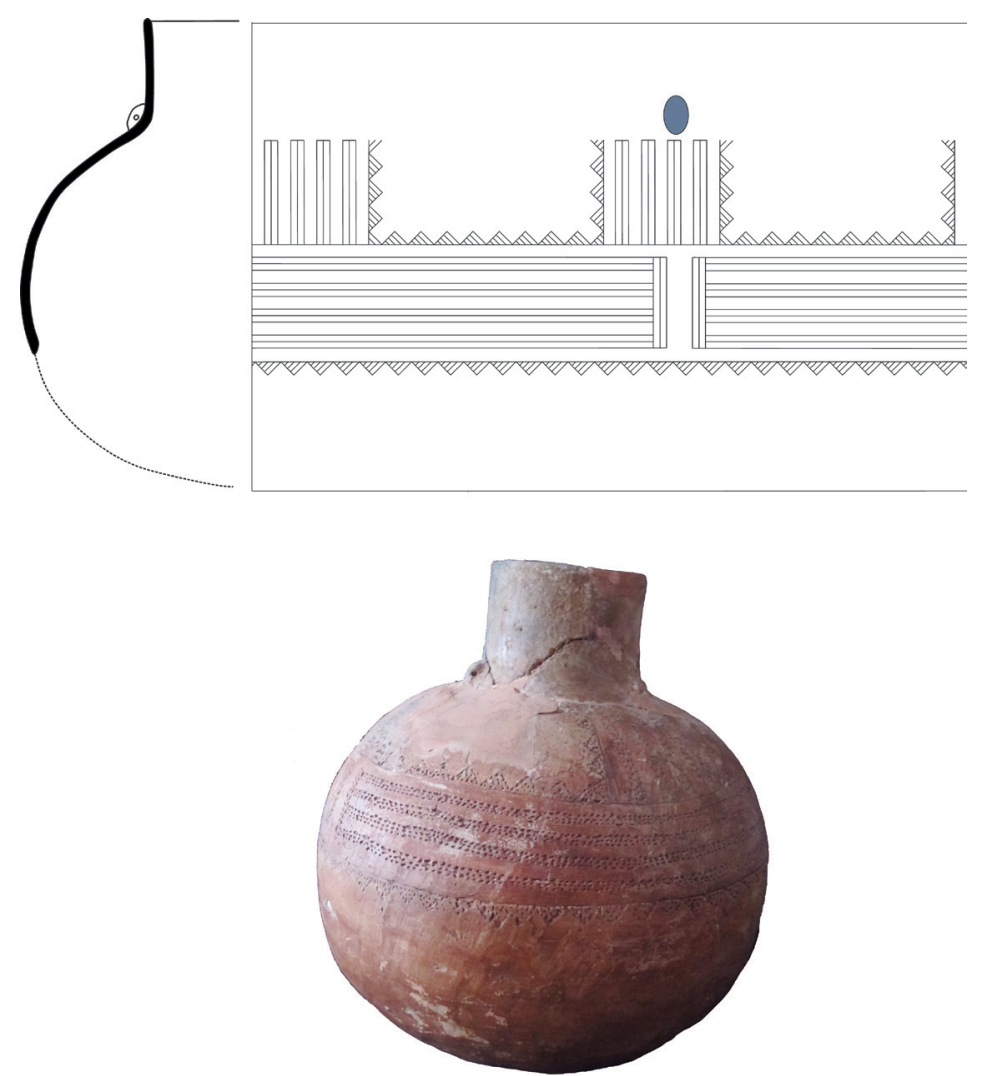

Figura 7: desarrollo de la composición decorativa del vaso cerámico de La Alcudia. Fuente: Fundación L’Alcúdia, Universidad de Alicante.

Se trata de un vaso de tendencia esferoide con cuello y una pequeña asa anular, con decoración impresa e incisa. En la zona justo por debajo del cuello se alternan dos tipos de decoraciones diferentes: por un lado bandas verticales delimitadas por trazos paralelos y rellenas de impresiones realizadas mediante un instrumento de punta simple; por otro, triángulos rellenos que se disponen en vertical y horizontal, formando cuadrados alternantes. Por debajo, y ocupando hasta la mitad del vaso, encontramos bandas horizontales delimitadas por trazos paralelos y rellenas de impresiones que no discurren de forma constante alrededor del vaso, sino que se cortan contra una banda vertical delimitada igualmente por trazos paralelos y rellena de impresiones. Encontramos hasta cuatro bandas horizontales, este espacio se encuentra delimitado por dos rectas largas incisas por abajo y por arriba. Bajo esta composición se desarrolla en horizontal y de forma continua triángulos invertidos rellenos por impresiones.

\section{b) La Cova de les Aranyes}

Otro de los yacimientos que encontramos en el Bajo Vinalopó es la Cova de les Aranyes del Carabassí, también conocida como la Cova del Frare. El yacimiento se sitúa en el cabo de Santa Pola, localizado en el sector norte de la cuenca del Bajo Segura. La cueva se emplaza en la vertiente nororiental de la sierra, en el margen izquierdo del Barranc del Frare, a unos 55 M. S.n.m. Presenta una larga secuencia estratigráfica, en la que se suceden periodos de baja intensidad, que arrancan en el Paleolítico, alternados con largos periodos de abandono (Hernández, Soler, Guilabert y Benito, 2013; Guilabert y Hernández, 2014).

Se trata de una cueva de planta irregular abierta al norte por una boca oval de unos dos metros de altura, que presenta una sala centra de 19×14 metros, junto a una serie de gateras. Los últimos trabajos de excavación fueron realizados en el 2000-2001, pero anteriormente se realizaron dos campañas, la primera en 1967 por Antonio Sáez Llorens, y en 1979 por Guillermo Iturbe Polo. En 
estas primeras campañas se describía un équido pintado en una de las paredes de la cavidad, que en 2001 se buscó su presencia sin éxito, encontrando solo una mancha roja que podía pertenecer a dicha pintura (Hernández et al., 2013).

En cuanto a los restos materiales, durante la últimas campañas se inventariaron 16.348 restos, donde predomina la fauna de pequeño tamaño, seguido de la malacofauna, la mesofauna, y en menor medida la cerámica a mano, fragmentos metálicos, industria lítica tallada, y de forma muy escasa, cerámica a torno -17 fragmentos-, ictiofauna, industria ósea, fauna de gran tamaña y restos humanos. Entre las cerámicas, destacan aquellas con decoraciones impresas no cardiales, realizadas con instrumentos de punta múltiple (Guilabert y Hernández, 2014).
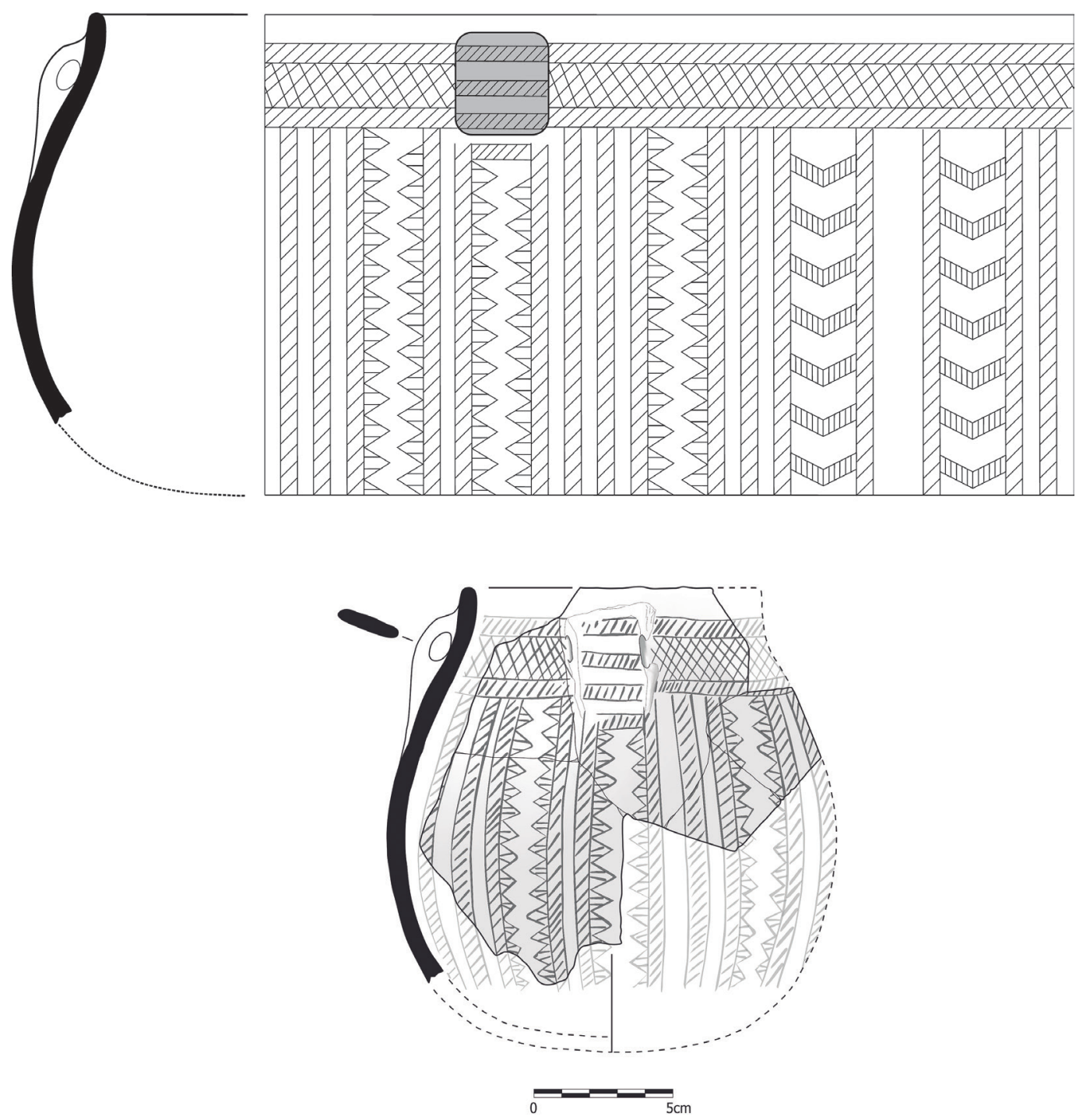

Figura 8: desarrollo de la composición decorativa del vaso cerámico de la Cova de les Aranyes. Fuente:

Ramos Molina, 1989, p. 171, fig. 5.

El vaso de la Cova de les Aranyes presenta una decoración realizada con técnica de incisión, donde en la parte superior aparece dos bandas horizontales delimitadas por trazos paralelos y rellenas de trazos oblicuos que envuelven, por arriba y por abajo, a una retícula con friso continuo de un ancho mayor. Por debajo de esta composición, y ocupando la totalidad del resto del vaso encontramos una serie de motivos que se alternan entre ellos: por un lado bandas verticales delimitadas por trazos paralelos y rellenas de trazos oblicuos; triángulos rellenos que se disponen 
de forma vertical junto a una de las pareles de las bandas verticales; y motivos en "V" rellenos de incisiones, más abiertos o más cerrados, dejando espacios sin decoración entre ellos de un tamaño similar a los rellenos. Por último, aparece relleno de pasta roja en el vaso.

\section{Resultados y comparación estilística: el valle del Vinalopó y el valle del Serpis}

Los yacimientos neolíticos a los cuales nos vamos a referir para la comparación estilística se encuentran en el norte de la provincia de Alicante. Esta área se estructura en tres regiones: la parte más oriental se organiza en una serie de valles paralelos entre sí, surcados por cauces fluviales de pequeño recorrido (Gallinera, Girona, Gorgos). El sector occidental se dispone alrededor del Riu d'Alcoi o Serpis, donde diversos valles interiores se estructuran en torno a la gran cubeta de Alcoi, atravesada por el río en sentido SO-NE. Al norte, encontramos valles más amplios (Vall d'Albaida) y una llanura costera más extensa. Aunque la cantidad de yacimientos es mayor, básicamente compararemos nuestros resultados con la Cova de la Sarsa, la Cova de les Cendres y la Cova de l'Or, puesto que son los yacimientos que han aportado más material cerámico, y por tanto han sido estudiados en mayor grado (Bernabeu, Gómez, Molina y García Borja, 2011b).

En el siguiente apartado expondremos los resultados del estudio comparativo entre los vasos estudiados del valle del Vinalopó y los conjuntos cerámicos del valle del Serpis. Para ello seguiremos el mismo orden que el presentado en la metodología empleada, hablando así de los elementos, composiciones, grupos y temas.

\subsection{Elementos y motivos}

En primer lugar, respecto al nivel inferior de análisis, que son los elementos, encontramos que los más dominantes en los vasos de estos yacimientos son el trazo corto $(A)$, seguido de lejos por la trazo recto largo $(B)$, el punto $(E)$ y el ángulo $(T)$, y con menor representatividad el trazo curvo. Así, el $40 \%$ de los elementos analizados en los vasos estudiados en el Serpis están realizados con el trazo corto y el 34\% por la recta (Bernabeu et al., 2011b).

En cuanto a los vasos estudiados en el presente trabajo, aun siendo solo seis, y por tanto su representatividad no es igual al estudio del estilo decorativo de las producciones cerámicas del Serpis, permiten mostrar una serie de consideraciones aproximadas. De este modo, los elementos que más se repiten coinciden en gran medida con los vasos del Valle del Serpis -el trazo recto largo (B) y el trazo corto (A)-, presentes ambos en la totalidad de los vasos estudiados. Por otro lado, encontramos dos motivos que no aparecen en las decoraciones cerámicas del valle del Serpis y que, por tanto, debemos entender como propias de la zona del Vinalopó. Se trata del triángulo (K) -lo encontramos en los vasos de Cova de les Aranyes, Ledua y La Alcudia-, y los motivos en "V" presentes en uno de los vasos del Arenal de la Virgen y en el vaso de la Cova de les Aranyes-. Por último, encontramos el elemento punto (E) en dos vasos, -Arenal de la Virgen y en Cueva Santa de Caudete-. Hay que decir que estos últimos dos vasos son impresos, uno realizado con gradina y otro cardial, y, por su ubicación geográfica en el Alto Vinalopó, parece lógica esta similitud en cuanto al uso del elemento punto en la decoración, pudiendo significar una proximidad a los conjuntos decorativos cardiales del Serpis. 


\section{ELEMENTOS SIMPLES}

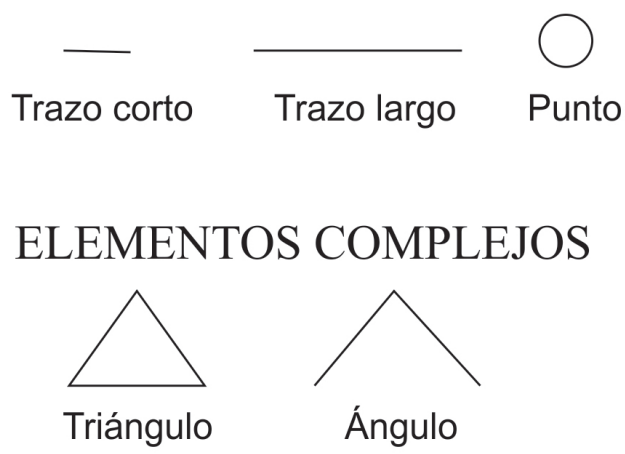

Figura 9: elementos presentes en los vasos del Vinalopó. Fuente: elaboración propia.

\subsection{Composiciones y grupos temáticos}

En segundo lugar, respecto a la complejidad de las composiciones, en los yacimientos del Serpis las composiciones son en su gran mayoría complejas. Esto ocurre igualmente en los recipientes pertenecientes al Vinalopó, donde los vasos de La Alcudia, Ledua, la Cova de les Aranyes y uno de los vasos del Arenal de la Virgen asocian en sus composiciones tres o más motivos, siendo por tanto de composición compleja.

Bandas no delimitadas

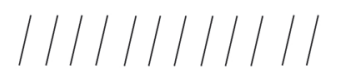

0000000000000000

Bandas delimitadas

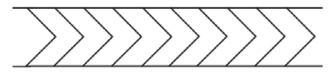

Frisos
Líneas

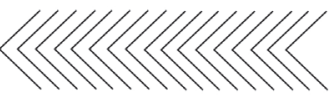

Mosaicos

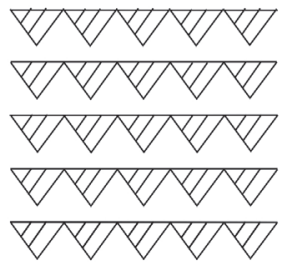

Líneas y bandas verticales
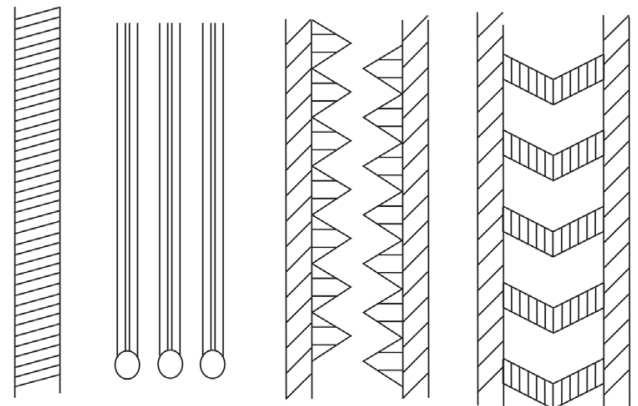

Figura 10: grupos compositivos definidos a partir del estudio de los vasos del Vinalopó. Fuente: elaboración propia. 
Para el estudio de los grupos estilísticos necesitamos observar los grupos temáticos, que atienden exclusivamente a la organización de la decoración sobre la superficie exterior del recipiente. Los vasos estudiados de yacimientos de la zona del Serpis han dado como resultado hasta seis grupos temáticos, que resumiremos a continuación. El grupo temático 1 está compuesto por líneas y bandas, son composiciones de lectura horizontal que recorren la superficie del vaso en sentido paralelo al borde. El grupo temático 2 es el de mosaicos, son decoraciones cuya estructura compositiva es un mosaico de manera que su motivo base se somete a traslación y/o traslación-reflexión tanto en horizontal como en vertical. El grupo temático 3 es el de los glifos, decoración de lectura mixta y cobertura total estructurada en campos adyacentes en los que alternan composiciones de lectura horizontal (bandas o líneas) o mixta (frisos) separadas por otras de lectura vertical (glifos). El grupo temático 4 son los frisos, decoración de lectura mixta y cobertura total o parcial pero ocupando al menos la mitad de la altura del recipiente. Su estructura organizativa es de campo único. El grupo temático 5 es de metopados y ortogonales, se trata de decoraciones de lectura mixta y campo único que tienden a ocupar la mitad, al menos de la altura del recipiente. Las composiciones horizontales y verticales que lo forman se organizan presentando un diseño ortogonal o metopado. También encontramos el grupo temático figurativo, caso especial, donde las composiciones de diverso tipo forman en conjunto un tema escénico. Por último, el grupo temático de los apliques (Bernabeu et al., 2011b).

\section{Lineas y Bandas}

1.1. Composición única

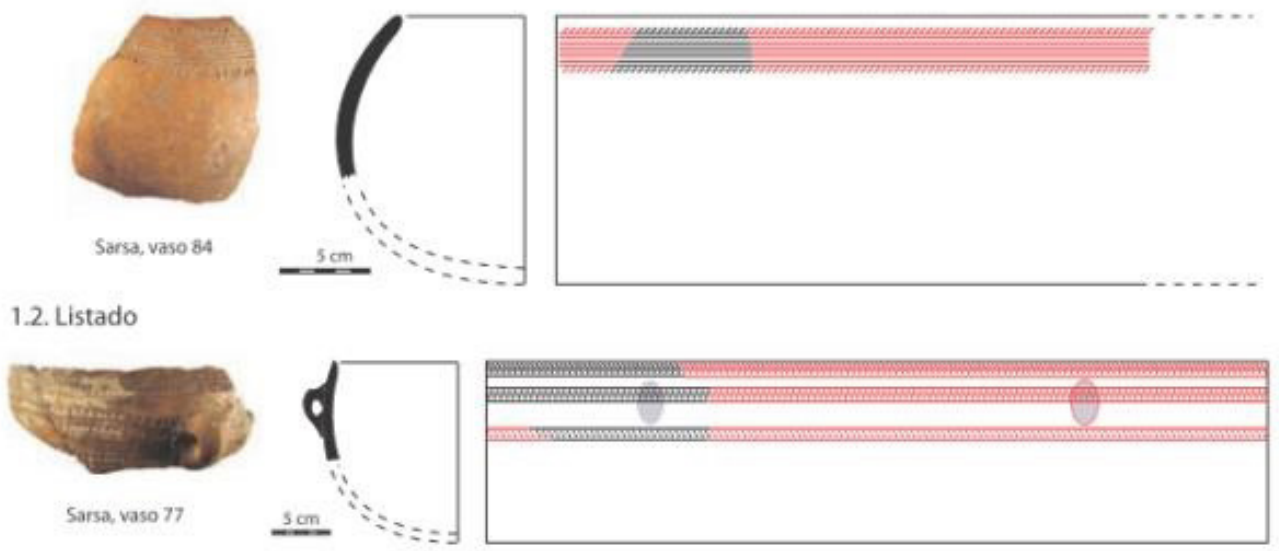

2. Mosaicos
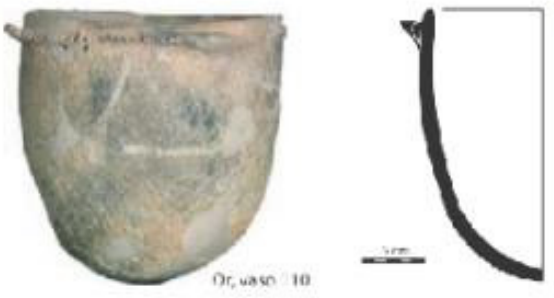

-

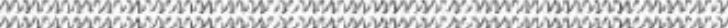

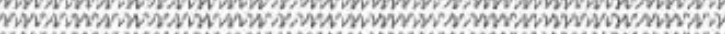

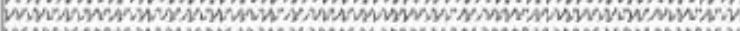

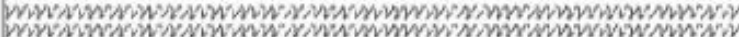

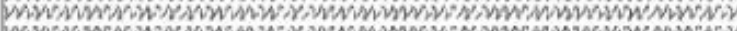

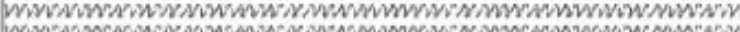
1ия (1)

3. Glifos

3.1. Glifos enfrentados
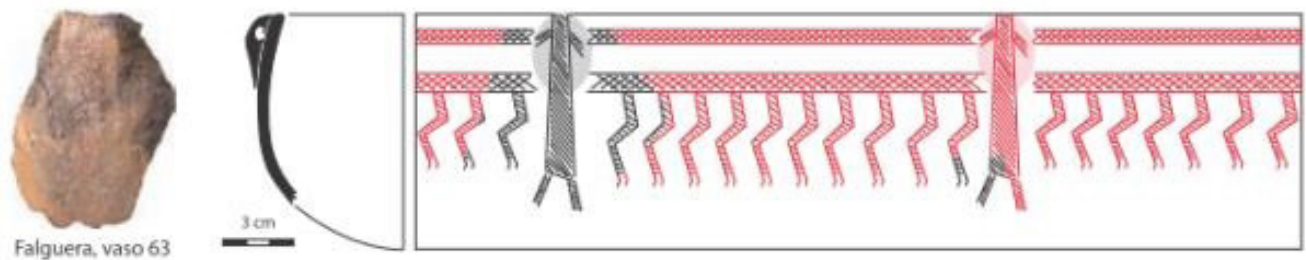

Panta Rei (2018), 9 - 32 


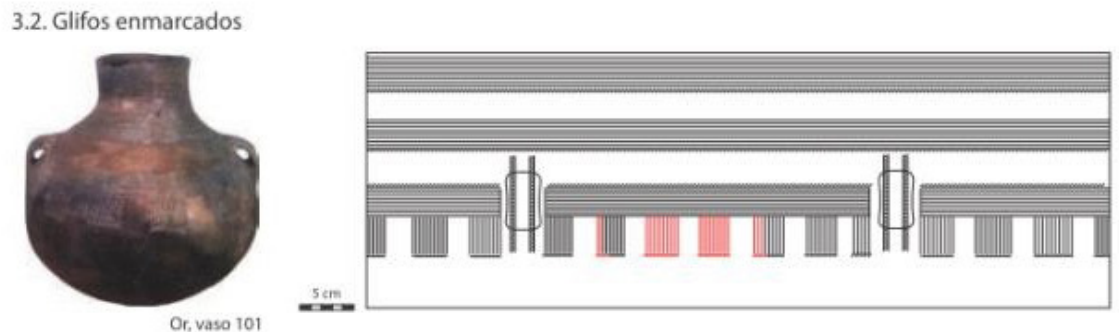

4.1. Frisos escénicos

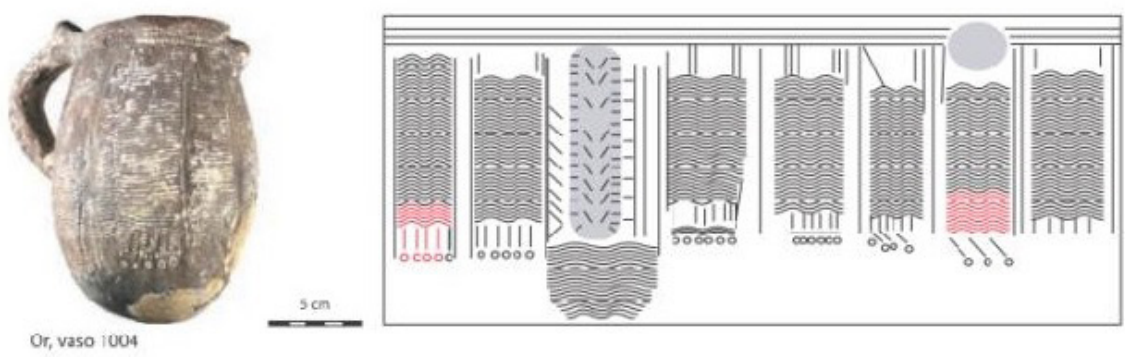

4.2. Frisos colgantes

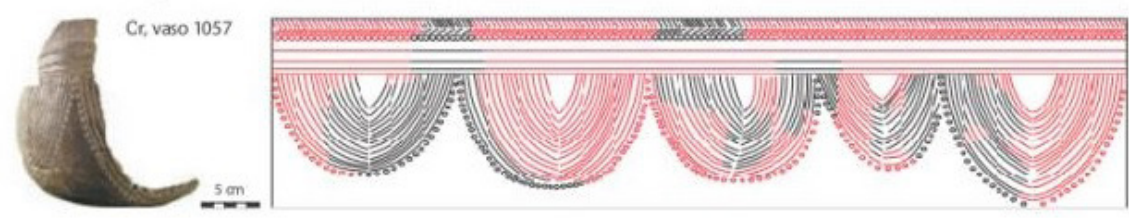

4.3. Ángulos y Festones

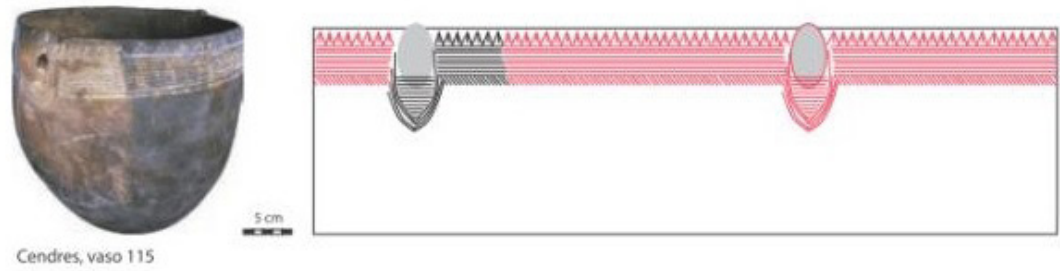

5. Metopados y Ortogonales

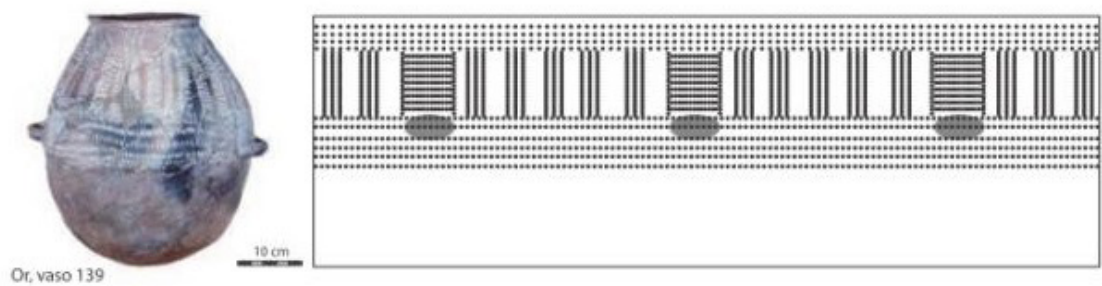

6. Apliques

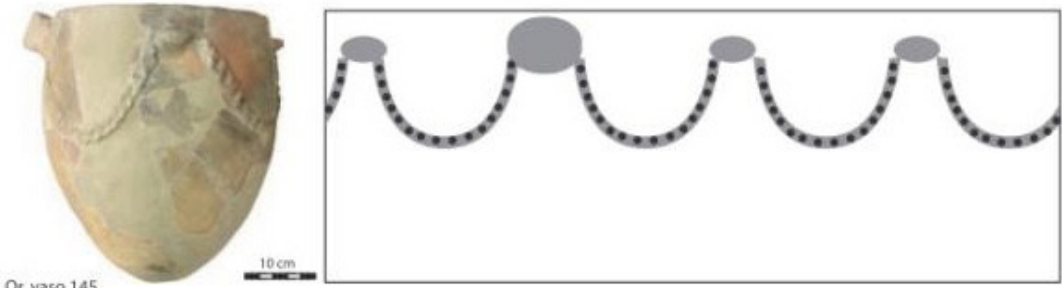

Figura 11: grupos temáticos de la zona del Serpis. Fuente: elaboración propia a partir de imágenes de Bernabeu Aubán et al., 2011, p. 163-170, fig. 7.11-7.18. 
Respecto a los vasos estudiados del Vinalopó, hemos podido identificar hasta 3 temas divididos algunos en subtemas, que no son en absoluto definitivos puesto que esta conclusión puede estar mediatizada por el tamaño de la muestra analizada, y únicamente son útiles para dar una idea de las diferencias existentes con el conjunto cerámico del valle del Serpis. Creemos, sin duda, que futuras investigaciones podrían confirmar, refutar o afinar los grupos temáticos aquí definidos.

- Grupo 1 de bandas horizontales: se trata de decoraciones formadas por composiciones de lectura horizontal que recorren la superficie del vaso en sentido paralelo al borde. Dentro de este grupo distinguimos dos a partir, básicamente, de la posición que ocupan en el vaso y por la extensión en éste.

-Subgrupo 1: una composición más simple formada únicamente por bandas limitadas y rellenas con trazos cortos, que se ubica en el cuello del recipiente cerámico. Ejemplo: vaso 1 del Arenal de la Virgen.

-Subgrupo 2: composiciones que forman bandas horizontales limitadas y rellenas por trazos cortos, que se desarrolla en el cuello del recipiente y en la parte central, coincidiendo con el recorrido que ocupan las asas. Ejemplo: vaso 2 del Arenal de la Virgen.

- Grupo 2: combina bandas horizontales delimitadas y rellenas con otros elementos de recorrido vertical, compuestos también por bandas delimitadas y rellenas, que se alternan con otras decoraciones.

-Subgrupo 1: combinación de bandas horizontales con bandas verticales. Ejemplo: vaso de la Cueva Santa, Caudete.

-Subgrupo 2: combinación de bandas horizontales con bandas verticales y otros motivos, que son triángulos con un desarrollo también vertical. Ejemplo: vaso de la Cova de les Aranyes.

-Subgrupo 3: combinación de bandas horizontales con bandas verticales intercalados con otros motivos, que son triángulos pero que tienen un recorrido horizontal. Este motivo en horizontal se relaciona con el asa. Ejemplo: vaso de Ledua.

- Grupo 3: composición de límite con lectura mixta, enmarcando el espacio decorativo, que ocupa solo la mitad del espacio del recipiente. Ejemplo: vaso de La Alcudia.

A partir de esto, si comparamos los recipientes cerámicos que comprende nuestro trabajo con los vasos cerámicos del valle del Serpis, vemos que algunos de estos grupos temáticos son comunes a ambos, como es el caso del grupo temático de bandas y líneas, donde encontramos los vasos de Arenal de la Virgen. El vaso de Cueva Santa de Caudete podría enmarcarse dentro del grupo temático de los glifos, puesto que presenta bandas horizontales combinados con otros elementos de lectura vertical. Los vasos de la Cova de les Aranyes y de Ledua podrían considerarse dentro del grupo temático de frisos, puesto que presentan un lectura mixta y una cobertura total del espacio, y se organizan en un campo único. Por último, el vaso de La Alcudia podría pertenecer al grupo compositivo de metopados, puesto que tiene una lectura mixta y ocupa la mitad del campo del recipiente.

Sobre estos datos, podemos hacer una serie de consideraciones. En primer lugar, vemos como el elemento triángulo $(\mathrm{K})$ no es propio del estilo decorativo de los yacimientos del valle del Serpis. También podemos observar como en los yacimientos de Arenal de la Virgen y Cueva Santa de Caudete no aparece este elemento triángulo, lo cual se podría atribuir a que estos yacimientos, que presentan cerámica con decoración impresa cardial, podrían estar relacionados, al menos inicialmente, con el grupo cardial del Serpis-Albaida. Sin embargo, en uno de los dos vasos de Arenal de la Virgen sí encontramos los elementos en " $V$ " o ángulo, que también aparecen en otros yacimientos del Vinalopó como la Cova de les Aranyes, realizado con la técnica incisa. Por otra parte, en los vasos cerámicos del Vinalopó no encontramos el grupo temático de los apliques, ni tampoco el grupo temático figurativo que si está presente en la zona del Serpis. 
GRUPO 1: bandas horizontales

- Subgrupo I

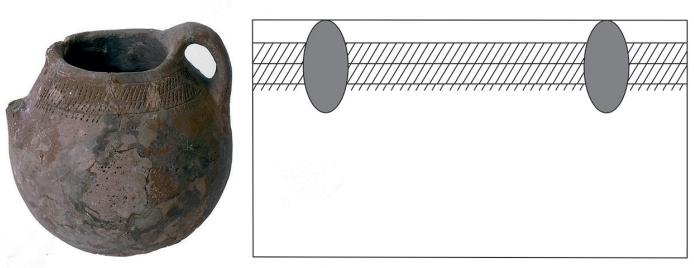

- Subgrupo II
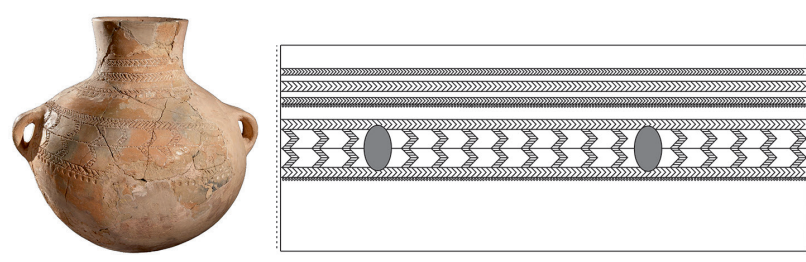

GRUPO 2: bandas horizontales y verticales - Subgrupo I

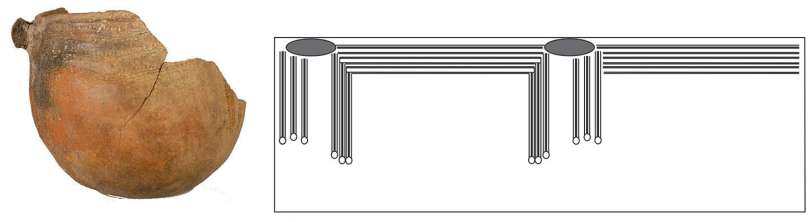

- Subgrupo II

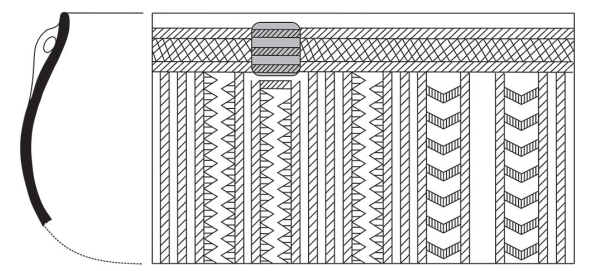

- Subgrupo III

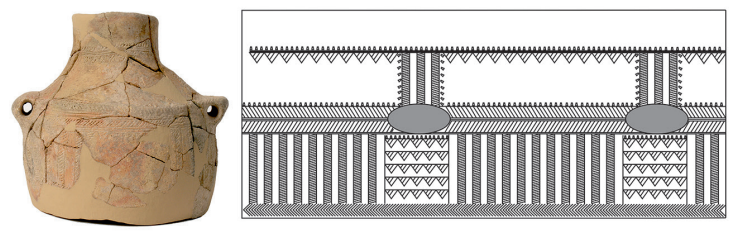

GRUPO 3: delimitados lectura mixta

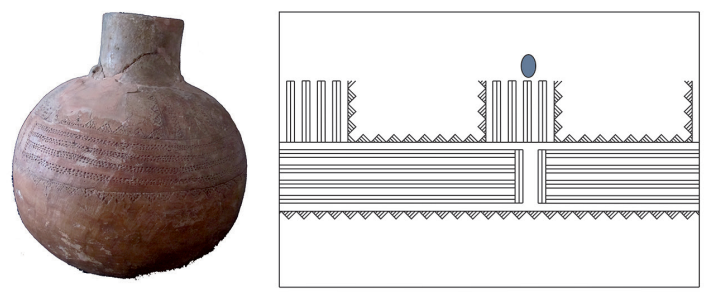

Figura 12: grupos temáticos definidos en la zona del Vinalopó. Fuente: elaboración propia.

\section{Consideraciones finales más allá de la decoración cerámica}

A partir del análisis decorativo de los vasos cerámicos de estos yacimientos, planteamos la existencia de dos estilos diferenciados, donde el factor para su división puede ser tanto de carácter cronológico como geográfico. El primero de los estilos correspondería con los yacimientos del valle del Serpis, caracterizado por la decoración impresa cardial y por una mayor complejidad en sus temas. Este estilo, de cronología más antigua -siglos centrales del VI milenio cal BC- marca las primeras cerámicas neolíticas levantinas y peninsulares, tratándose de los llamados grupos neolíticos puros. El segundo estilo correspondería a los yacimientos del valle del Vinalopó, teniendo una cronología de ocupación más reciente, finales del VI milenio cal BC y consolidada en el V milenio BC. Esta cerámica muestra diferencias importantes respecto a las primeras cerámicas cardiales. En primer lugar, la cerámica impresa cardial no es tan abundante, y en segundo lugar, tanto los elementos utilizados para las composiciones decorativas, como los temas desarrollados presentan algunas diferencias, aunque no debemos olvidar que las semejanzas también están presentes. De esta forma, la similitud estilística entre dos grupos podría estar relacionada con la intensidad de los contactos entre ambas zonas culturales. Aunque, como nos dice Hodder (1977), aun en situaciones de interacción social intensa, la cultura material permite mantener límites sociales entre grupos y reflejar pautas de identificación. Este autor sostiene que es posible la existencia de grupos con una cultura material distintiva, aunque interactúen entre sí frecuentemente.

Así, podemos relacionar el concepto de estilo con el concepto de cultura, concebida como un conjunto de normas y valores compartidos que caracteriza a un determinado grupo social o étnico 
y que se refleja en lo material a través de conjuntos de objetos con atributos formales semejantes, que definimos como estilos, identificando cada estilo a una cultura (Runcio, 2007). Igualmente, también se puede relacionar el concepto de barreras o límites sociales (social boundaries), pudiendo hablar de la existencia de barreras sociales cuando las opciones tecnológicas y otros aspectos de la cultura material son diferentes entre dos comunidades (Hegmon, 1998). Aunque debemos tener en cuenta que muchas veces simplemente una diferencia en cuanto a la forma de realizar determinados objetos materiales, en este caso la decoración cerámica, no es suficiente para hablar de límites sociales acotados, y es necesario aportar más información para justificar esa frontera étnica (Hegmon, 1998). Por esta razón, existe un debate acerca de si el Estilo puede ser o no determinante para trazar limites sociales o étnicos.

Por todo esto, queremos introducir otro factor más de diferenciación que puede aportar algo más de luz acerca de la existencia o no de una barrera social entre las dos comunidades que hemos tratado: la presencia o no de Arte Esquemático y Macroesquemático. Para este hecho, se puede entender el arte rupestre desde una perspectiva territorial, como una evidencia material del interés de las comunidades prehistóricas de marcar su presencia en el territorio, y como una forma de reconocer los límites entre diferentes grupos sociales, o de reconocer las relaciones existentes entre diferentes comunidades. Por otro lado, debemos tener en cuenta también que estas imágenes, además de su valor estético, tienen un valor simbólico y reflejan el mundo religioso de aquellos que las realizaron, por lo que se pueden considerar como indicadores etnológicos.

En primer lugar, el Arte Macroesquemático delimita una zona comprendida entre el Benicadell, Aitana y Mariola, donde se localizan 18 abrigos conocidos hasta el momento, además de varias cuevas de habitación que nos ofrecen materiales cerámicos donde su decoración reproduce motivos semejantes a las pinturas. Así podemos relacionar espacialmente el territorio cardial y el territorio macroesquemático, que podría mostrar el reflejo simbólico de la ocupación de los primeros grupos neolíticos (Hernández, 2000a; 2006a; 2016).

En segundo lugar, el Arte Esquemático tiene un patrón de localización mucho más amplio, también porque se trata de una manifestación de larga duración, permitiendo las técnicas decorativas empleadas en la ejecución de estos motivos sobre recipientes cerámicos situarla cronológicamente en los momentos iniciales del Neolítico (Galiana y Torregrosa, 2001), y pudiendo estar relacionado con la expansión de las comunidades neolíticas sobre los territorios vecinos al área de colonización inicial. La localización de los motivos como antropomorfos en doble "Y", en " $X$ ", soliformes, ramiformes, entre otros, se concentra tanto en Albacete, como en Murcia, en las tierras aragonesas, y en tierras valencianas. En éstas últimas, las manifestaciones se pueden dividir en cuatro grupos: el grupo 1 incluye las cuencas de los ríos Serpis, Albaida y Canyoles; el grupo 2, los abrigos del curso medio del Júcar; el grupo 3, abarca la zona entre los ríos Turia y Palencia; y el grupo 4, la Rambla de la Viuda, y els Ports, en Castellón (Torregrosa, 2000-2001). La mayor concentración de Arte Esquemático coincide, de nuevo, con el área de mayor agrupación de yacimientos cardiales (Jover et al., 2008).

Tanto el AE como el AM Se podrían considerar como un indicador, junto con la cultura material, y especialmente la cerámica, que delimitaría el territorio en el que se consolidó inicialmente el grupo cardial. Pero hay que tener en cuenta que el AE, pese a su gran distribución, no debe considerarse como un indicador étnico en su conjunto, puesto que existen diferencias regionales y cronológicas en cuanto a los temas y las composiciones representadas. En cambio, la pintura macroesquemática y la significación simbólica que la rodea sí se puede entender como el indicador de la existencia de una zona socialmente diferenciada, en torno a las primeras poblaciones neolíticas, con unas costumbres propias, marcadas en este caso por la religiosidad. Aunque se debe tener en cuenta que la zona de AM se ha visto ampliada a raíz de las evidencias de arte rupestre con características similares al AM en la cuenca del Júcar, entre los que destaca la Cueva del Tío Modesto y la Cueva de la Araña. A partir de estos yacimientos se ha planteado que los motivos representados estarían relacionados con los macroesquemáticos alicantinos. Hay que tener en cuenta que estos abrigos no corresponden con las primeras ocupaciones neolíticas, sino con la fase de expansión de las 
comunidades cardiales alicantinas, por lo que se trata de un territorio de influencia macroesquemática, donde posiblemente se haya perdido parte del contenido simbólico, pero no las características formales (Hernández, 2006b).



Figura 13: localización de los abrigos con AM y AE y su relación con los yacimientos cardiales (García Atiénzar, 2007, p. 883, fig. 208).

Con estos datos, la presencia de Arte Macroesquemático y de Arte Esquemático en la zona del valle del Serpis, relacionado íntimamente con la presencia de los primeros neolíticos, junto con el estilo decorativo cerámico que hemos descrito antes, nos permite hablar, a modo de hipótesis, de una frontera social entre ésta zona y el valle del Vinalopó, que presenta un estilo decorativo cerámico diferente, caracterizado por el uso del elemento Triángulo. Además de lo anterior, debemos añadir que en la zona del Vinalopó, no se habían documentado evidencias de Arte Esquemático, ni tampoco de Arte Macroesquemático, a pesar de ser una zona bien conocida arqueológicamente. Pero sí encontramos representaciones artísticas consideradas de influencia macroesquemáticos (Hernández, 2006b) en la cuenca del Júcar y en el alto y medio Segura, hecho que sería reflejo de la neolitización en las zonas que más pronto evidencian la presencia de elementos neolíticos (García Atiénzar, 2010).

Sin embargo, en este sentido, queremos destacar el hallazgo de varios motivos de Arte Esquemático en la Cueva Santa de Caudete, de entre los que cabe destacar un motivo antropomorfo en doble "Y" (Aguilar, 2014). Si bien estas representaciones aún se encuentran en vías de estudio 
por miembros de la Universidad de Alicante, queremos incidir que la presencia de este motivo, tradicionalmente vinculado al territorio cardial, aproximaría el Alto Vinalopó al grupo del Serpis, conexiones que también podían rastrearse a partir del estilo decorativo cerámico. Así, vemos similitudes estilísticas y tipológicas entre el vaso estudiado de la Cueva Santa de Caudete con el vaso 291 de la Cova de la Sarsa (García Borja, 2015). Y sumado a ello, encontramos representaciones de arte esquemático similares, apareciendo también un motivo antropomorfo en doble " $Y$ " en la Cova de la Sarsa.

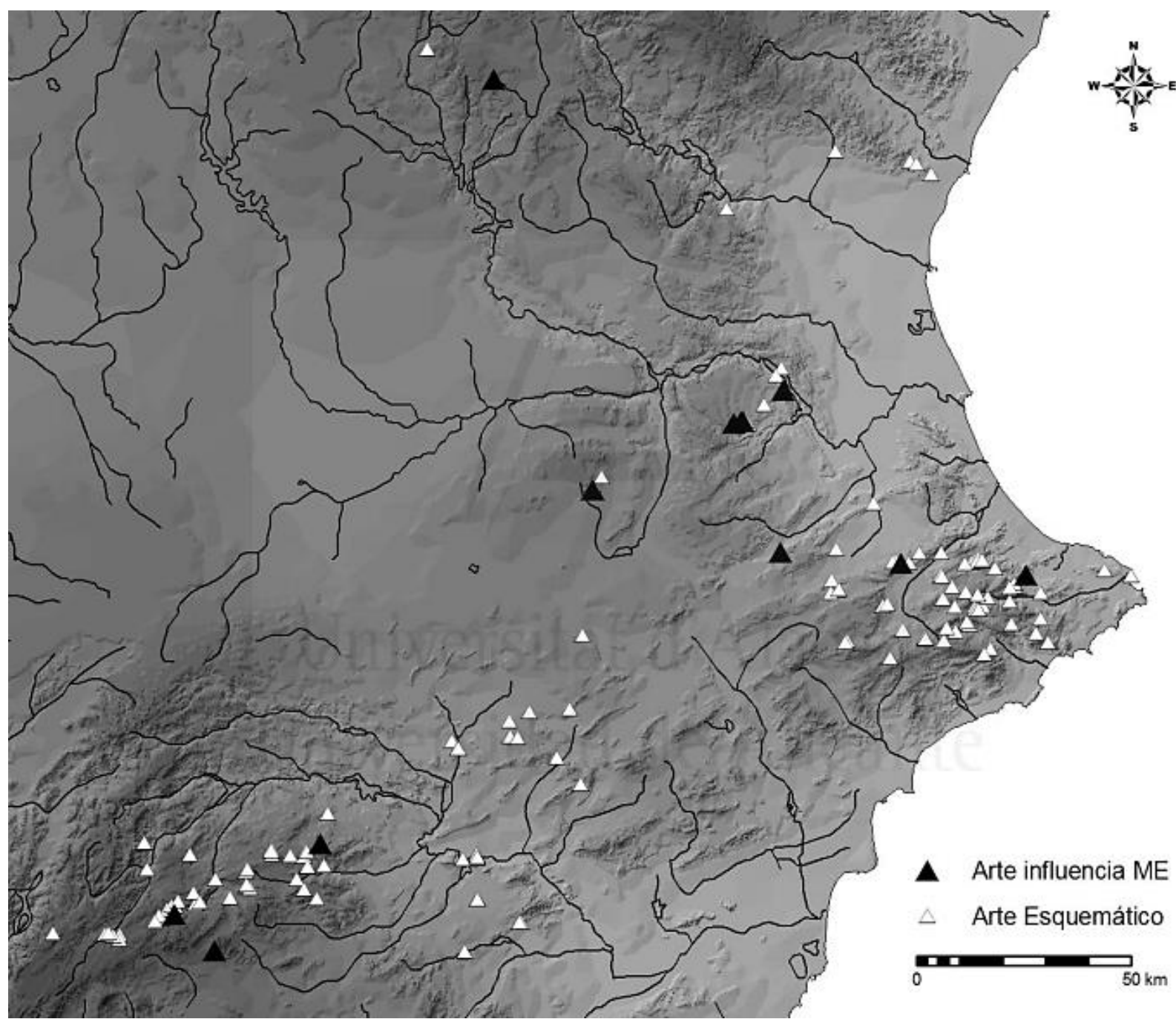

Figura 14: localización de los abrigos con arte de influencia macroesquemática (García Atiénzar, 2007, p. 892, fig. 211).

Estas relaciones nos permiten proponer, a modo de hipótesis, que la implantación de las primeras comunidades neolíticas en el Vinalopó fue protagonizada por grupos cardiales cuyo origen cabría situar en el Valle de Albaida. Con los datos actualmente disponibles, resulta imposible establecer en qué momento se produjo este asentamiento, aunque la existencia de elementos estilísticos propios del grupo cardial Or-Cendres en Arenal de la Virgen o Cueva Santa de Caudete permiten proponer una fecha ca. 5400-5200 cal BC. Además, por la situación geográfica de los yacimientos neolíticos nombrados del Alto Vinalopó y por las similitudes con el grupo neolítico de Sarsa se podría hablar de relaciones entre ambas comunidades o incluso tratarse de una escisión de familias (García Borja, 2015). Tras esta colonización inicial del Vinalopó, la expansión de los grupos neolíticos debió seguir una deriva norte-sur, tal cual estarían mostrando los repertorios 
cerámicos de los asentamientos del Medio y Bajo Vinalopó. La cronología de este proceso también resulta compleja de establecer, aunque los resultados de la intervención realizada en la calle Colón de Novelda (García Atiénzar et al., 2006) permite situarla a lo largo del último tercio del VI milenio cal BC. Los nuevos grupos asentados en este territorio presentan un Estilo decorativo con notables diferencias con respecto a aquellos asentados en el Alto Vinalopó. Estas diferencias, y el hecho de que en estos tramos del valle no se hayan constatado manifestaciones rupestres, permite plantear la existencia de un proceso de reformulación cultural (creación de nuevos códigos de identificación grupal) similar al advertido en aquellos lugares de implantación inicial neolítica a lo largo de la expansión de las sociedades campesinas por las costas del Mediterráneo (García Atiénzar, 2010). Este proceso estaría relacionado, por tanto, con el llamado modelo arrítmico de Guilaine (20002001) que propone ritmos diferentes en el avance de las poblaciones neolíticas, ritmos que estarían marcados por la adaptación a nuevas condiciones ambientales y económicas, produciéndose así avances más rápidos y otros ralentizados. Estos ritmos más pausados se observarían en los lugares donde surge un cambio en el registro tecnológico, económico e ideológico, apareciendo así zonas de frontera cultural como el que hemos tratado de observar para buena parte del valle del Vinalopó. Este nuevo espacio social quedaría definido arqueológicamente a través de un nuevo conjunto de rasgos-decoración cerámica, manifestaciones artísticas, etc.- que guardarían ciertas semejanzas con respecto a al grupo cardial original, aunque con características propias.

\section{Bibliografía}

Aguilar, S. (2014). La reciente aparición de pinturas rupestres en la Cueva Santa. La Calle de Caudete. Recuperado de http://www.caudetelacalle.es/noticia.asp?idnoticia=89448

Berg P. L. (1994). Grammaire des styles céramiques du Rubanné d'Alsace. Zimmersheim: Association pour la Promotion de la Recherche archéologique en Alsace.

Bernabeu, J. (1989). La tradición cultural de las cerámicas impresas en la zona oriental de la península ibérica. Serie de Trabajos Varios, 86. Valencia: Diputación Provincial de Valencia.

Bernabeu, J., García Borja, P., Gómez, O., y Molina, L. (2011a). El componente decorativo en las producciones cerámicas. En VV. AA., Las primeras producciones cerámicas en el VI milenio Cal aC en la Península Ibérica. Saguntum extra-12, (pp. 17-34). Valencia: Universidad de Valencia.

Bernabeu, J., Gómez, O., Molina, L. y García Borja, P. (2011b). La cerámica neolítica durante el vi milenio Cal AC en el Mediterráneo central peninsular. En VV. AA., Las primeras producciones cerámicas en el VI milenio Cal aC en la Península Ibérica. Saguntum extra-12 (pp. 153-179). Valencia: Universidad de Valencia.

Bernabeu, J. y Molina, LI. (Eds.) (2009). La Cova de les Cendres (Moraira-Teulada, Alicante). Serie Mayor, 6. MARQ. Alicante: Museo Arqueológico de la Diputación de Alicante.

Bernabeu, J., Molina, LI., Guitart, I. y García-Borja, P. (2009). La cerámica prehistórica: metodología de análisis e inventario de materiales. En J. Bernabeu y LI. Molina. (Eds.), La Cova de les Cendres (Moraira-Teulada, Alicante) (pp. 50-178 del CD). Serie Mayor, 6. MARQ. Alicante: Museo Arqueológico de la Diputación de Alacant.

Bernabeu, J., Orozco, T. y Díez, A. (2012). Mas d'ls y las construcciones con fosos del VI al III milenio cal a.C. En VV. AA., MARQ. Arqueología y Museo, 5 (pp. 53-72). Alicante: Museo Arqueológico Provincial de Alicante.

Constantin, C. (2000). Structure des productions céramiques et chaînes opératoires. En D. Binder y J. Courtin. (Eds.), Terre cuite et société. La céramiques document technique, économique et culturelle. XIV Rencontres Internationales d'archéologie et d'histoire d'Antibes (Octubre, 1993) (pp. 241-253). Association pour la Promotion et la Diffusion des Connaissances Archéologiques.

Fernández, J., Gómez, M., Ferrer, C. y YII, R. (2011) El Arenal de la Virgen (Villena, alicante), primer asentamiento perilacustre del mesolítico de muescas y denticulados en la península ibérica: 
datos culturales, cronoestratigráficos y contextualización paleoambiental. Zephyrus, LXVIII, 87-114.

García Atiénzar, G. (2007). La neolitización del territorio. El poblamiento Neolítico en el área central del Mediterráneo español. Alicante: Universidad de Alicante.

García Atiénzar, G. (2010). Las comarcas centromeridionales valencianas en el contexto de la Neolitización de la fachada noroccidental del Mediterráneo. Trabajos de Prehistoria, 67, 1, 37-58.

García Atiénzar, G., Jover, F. J., Ibáñez, C., Navarro, C. y Andrés, D. (2006). El yacimiento Neolítico de la Calle Colón (Novelda, Alicante). Recerques del Museu d'Alcoi, 15, 19-28.

García Atiénzar, G. y Jover, F. J. (2014). Hipótesis sobre el proceso de implantación de los primeros grupos neolíticos en las comarcas centromeridionales valencianas. En F. J. Jover, P. Torregrosa y G. García Atiénzar (Eds.), El Neolítico en el Bajo Vinalopó (Alicante, España) (pp. 29-38). Oxford: Archaeopress.

García Borja, P., Aura, E., Bernabeu, J. y Jordá, J. (2010). Nuevas perspectivas sobre la neolitización en la cueva de Nerja (Málaga-España): la cerámica de la sala del vestíbulo. Zephyrus, 66, 109-132.

García Borja, P., Cortell, E., Pardo, S. y Pérez, G. (2011). Las cerámicas de la Cova de l'Or (Beniarrés, Alacant). Tipología y decoración de las colecciones del Museu d'Alcoi. Recerques del Museu D'Alcoi, 20, 71-138.

García Borja, P. (2015). El estilo de la cerámica neolítica de la Cova de la Sarsa (Bocairent, València). Tesis doctorales de la Universidad de Valencia.

Gómez, M. y Fernández, J. (2016). El yacimiento Neolítico del Arenal de la Virgen (Villena, Alicante): estudio de la colección de materiales de José María Soler. Bilyana, 1, 17-30. Villena, Alicante: Museo Arqueológico "José María Soler".

Gosselain, O. P. (1992). Technology and Style: Potters and Pottery Among Bafia of Cameroon. Man, New Series, Vol. 27, 3, 559-586.

Guilabert, A., Jover, F. J. y Fernández, J. (1999). Las primeras comunidades agropecuarias del Río Vinalopó (Alicante). En VV.AA, Actas del Il Congreso del Neolítico en la Península lbérica (pp. 283-290). Saguntum- Extra-2. Valencia.

Guilabert, A. P. y Hernández, M. S. (2014). La cova de les Arayes (o del Frare) del Carabassí (Santa Pola). En F. J. Jover, P. Torregrosa. y G. García Atiénzar (Eds.), El Neolítico en el Bajo Vinalopó (Alicante, España) (pp. 55-92). Oxford: Archaeopress.

Guilaine, J. (2000-2001). La diffusion de l'agriculture en Europe: une hypothèse arythmique. Zephyrus, 267-272.

Hernández, M. S. (1997). Agua, río, camino y territorio. A propósito del Vinalopó. En M. C. Rico (coord.), I Congreso de Estudios del Vinalopó (p. 17-34). Petrer: Centro de Estudios Locales del Vinalopó.

Hernández, M. S. (2000). Sobre la religión neolítica. A propósito del Arte Macroesquemático. En Scripta in Honorem Enrique Llobregat Conesa, Vol.1 (pp. 137-155). Alicante: Instituto Alicantino de Cultura Juan Gil-Albert.

Hernández, M. S. (2006a). Artes esquemáticos en la Península Ibérica: el paradigma de la pintura esquemática. En J. Martínez y M. S. Hernández (coords.), Actas del Congreso de Arte rupestre esquemático en la Península Ibérica (pp. 13-32). Alicante: Instituto Alicantino de Cultura Juan Gil-Albert.

Hernández, M. S. (2006b). Arte esquemático en la fachada oriental de la Península Ibérica. 25 años después. Zephyrus, 137-155.

Hernández, M. S. (2016). Arte Macroesquemático vs. Arte Esquemático. Reflexiones en torno a una relación intuida. En VV.AA, Serie Trabajos Varios del SIP, nº 112 (p. 481-490). Valencia: Diputación Provincial de Valencia.

Hernández, M. S. y Alberola, E. (1988). Ledua (Novelda, Alacant): un yacimiento de llanura en el Neolítico Valenciano. Archivo de Prehistoria Levantina, XVIII, 149-158. 
Hernández, M. S. y Martí, B., (2002). El Arte Rupestre en la fachada Mediterránea. Entre la tradición epipaleolítica y la expansión neolítica. Zephyrus, 53-54, 241-265.

Hernández, M. S., Soler, J. A., Guilabert, A. P. y Benito, M. (2013). La Cova de Les Aranyes del Carabassí. Distintas carpetas de una investigación imprescindible para el conocimiento de la prehistoria del litoral meridional de Alicante. En VV. AA., Santa Pola, arqueología y museo: Museos municipales en el MARQ (pp. 102-119). Alicante: Museo Arqueológico de la Diputación de Alicante.

Hegmon, M. (1998). Technology, Style, and Social Practices: Archaeological Approaches. En M. T. Stark (Ed.), The Archaeology of Social Boundaries (pp. 264-279). Washington-London: Smithsonian Institution Press.

Jover, F. J., Molina, F. J. y García Atiénzar, G. (2008). Asentamiento y territorio. La implantación de las primeras comunidades agropastoriles en las tierras meridionales valencianas. En VV. AA, Actas del IV Congreso del Neolítico Peninsular (pp. 90-97). Alicante: Fundación MARQ. Diputación de Alicante.

Manen, C. (2002). Structure et identité des styles céramiques du Néolithique ancien entre Rhône et Ėbre. Gallia Préhistoire, 44, 121-165.

Martí, B. y Hernández, M. S. (1988). El Neolític Valencià: Art rupestre i cultura material. Valencia: Diputación Provincial de Valencia.

Pérez, L. (1993). El yacimiento Neolítico de la Cueva Santa (Caudete). Revista de Fiestas de Moros y Cristianos (no paginado).

Prieto, M. P. (1998). Forma, estilo y contexto en la cultura material de la Edad del Bronce gallega: cerámica campaniforme y cerámica no decorada. Santiago de Compostela: Universidad de Santiago de Compostela.

Prieto, M. P. (1999). Caracterización del estilo cerámico de la edad del bronce en Galicia: cerámica campaniforme cerámica no decorada. Complutum, 10, 71-90.

Prieto, M. P. (2003). La cerámica neolítica en Galicia. Estudio de síntesis desde la perpectiva de la Arqueología del Paisaje. En VV.AA, Actas de III Congreso del Neolitico en la Península Ibérica (pp. 337-348). Santarder: Universidad de Cantabria.

Runcio, M. A. (2007). El estilo en Arqueología: diferentes enfoques y perspectivas. Espacios de crítica y producción, 36, 18-28.

Sackett, J. R. (1977). The meaning of Style in Archaeology: A General Model. American Antiquity, 42, 3, 369-380.

Soler, J. A. y López, J. A. (2000-2001). Nuevos datos sobre el poblamiento entre el Neolítico y la Edad del Bronce en el sur de Alicante. Lvcentvm, XIX-XX, 7-26.

Soler, J. M. (1965). El Arenal de la Virgen y el Neolítico Cardial en la comarca Villenense. Revista Anual Villenense, 15, 32-35.

Torregrosa, P. y Galiana, F. (2001). El arte Esquemático del Levante peninsular: Una aproximación a su dimensión temporal. Millars, espai i historia, 24, 153-198.

Torregrosa, P., Jover, F. J. y López, E. (dirs.) (2011). Benàmer (Muro de l'Alcoi, Alicante). Mesolíticos y neolíticos en las tierras meridionales valencianas. Serie Trabajos Varios del SIP, no 112. Valencia: Diputación Provincial de Valencia. 


\section{Panta Rei}

PANTA REI es una revista digital de investigación orientada a la Historia y otras ciencias afines. Su principal objetivo es la transmisión del conocimiento científico, dando una oportunidad también a los jóvenes investigadores que quieren abrirse camino en el estudio de las ciencias humanas y sociales. Se compone de estudios originales relacionados con la disciplina histórica así como su didáctica y difusión. Las diferentes secciones que componen la revista son: artículos de investigación, entrevistas a profesionales, recensiones de monografías de actualidad y crónicas de congresos o eventos científicos relevantes.

Todos los artículos publicados son objeto de un proceso de revisión a cargo de un mínimo de dos evaluadores, que se consideran expertos en el ámbito temático del artículo propuesto. Nuestro deseo es poder ofrecer unos contenidos rigurosos, de calidad y de interés.

EI CEPOAT (Centro de Estudios del Próximo Oriente y la Antigüedad Tardía de la Universidad de Murcia) es la institución encargada de la coordinación y gestión de la revista, desde donde anualmente se lanzará la convocatoria para aquellos que estén interesados en publicar sus trabajos, siempre relacionados con la Historia, Arqueología, Historia del Arte, Didáctica de las Ciencias Sociales, etc.

PANTA REI is a digital journal focused on History and other sciences related to it. Its main objective is the transmission of scientific knowledge by giving also an opportunity to young researchers who want to make their way in the study of human and social sciences. It is composed by original studies related to History, as well as its didactics and promotion. The different sections of this journal are: research articles, interviews to professionals, recensions on monographs about current issues and reports about congresses or relevant scientific events.

All the articles published are subject to a revision process carried out by a minimum of two reviewers who are considered to be experts in the field of the article proposed. Our wish is to offer rigorous contents with quality and being of interest to the reader.

CEPOAT (Centre of Studies of the Middle East and Late Antiquity of the University of Murcia) is the institution in charge of the coordination and management of this journal. This is the centre from where the call for papers will be launched for all the people interested in publishing their papers, always related to History, Archeology, Art History, Didactics of the Social Sciences, etc. 


\section{Normas de Publicación}

El autor se compromete a enviar trabajos originales, que no se encuentren publicados en otras revistas ni en otros idiomas. Así mismo, el mismo artículo no podrá ser presentado en otras revistas mientras dure el proceso de evaluación.

\section{Envío y presentación de originales}

Los artículos se enviarán exclusivamente a través del correo electrónico a la dirección pantarei@um.es. Los textos serán enviados en formato DOC y las imágenes en formato JPEG o TIFF, y con un tamaño mínimo de 2000 px. Éstas no aparecerán incorporadas en el texto, sino enviadas en archivo aparte y correctamente numeradas según su posición en el texto. Junto al trabajo, se rellenará y enviará un documento aparte en el que se especifiquen los datos del autor siguiendo el modelo disponible en la página Web de la revista.

Para la redacción de los trabajos se tendrá en cuenta el Manual de la American Psychological Association, en su sexta edición. La extensión máxima de los trabajos será de 30 páginas. La tipografía será Arial 11, con interlineado sencillo y sin espacio alguno entre párrafos. El texto deberá ir justificado a ambos márgenes y sin sangría en los primeros párrafos. Los márgenes serán de $2,50 \mathrm{~cm}$. En los casos en los que fuera necesario incorporar notas, éstas irán a pie de página, enumeradas consecutivamente, con tipografía Arial 10, interlineado sencillo y justificadas a ambos márgenes.

Una información más detallada se encuentra disponible en la página http://www.um.es/cepoat/ pantarei.

\section{Proceso de valoración y evaluación}

Una vez recibidos los trabajos, la Revista realizará una primera valoración. Si el trabajo enviado se ajusta a las normas de presentación propuestas, la temática es coincidente con la línea editorial de la revista y posee la calidad científica necesaria, será remitido al consejo asesor para una primera evaluación. Si no es así en este primer paso se puede rechazar directamente los documentos que incumplan claramente la línea editorial.

Será el Consejo Asesor quien indique a la revista la originalidad, relevancia, estructura, redacción, aparato bibliográfico, etc. del trabajo enviado y, para ello, se designará a dos revisores expertos externos que evaluarán cada uno de los trabajos, que pueden formar parte (o no) de este Consejo Asesor. La selección de los revisores se ajustará a la temática y características metodológicas del trabajo. El nombre y filiación de los autores serán eliminados del trabajo para su revisión, así como los revisores actuarán de manera anónima y confidencial.

Los revisores deberán rellenar un informe de evaluación que centrará su atención en aspectos tales como características formales, originalidad y novedad de los trabajos, relevancia de las propuestas y los resultados, calidad metodológica y validez científica.

Una vez terminado el proceso se decidirá la aceptación o no de los mismos y su publicación en el número que sea pertinente, así como las modificaciones susceptibles de ser realizadas para su final publicación. Dicha notificación se enviará únicamente por correo electrónico, en un plazo máximo de seis meses. 


\section{Publishing rules}

The author is committed to submit original papers not having been published in other reviews or in other languages. In this way, it is not allowed for the same paper to be presented in other reviews during the evaluation process.

\section{Submission and presentation of originals}

The articles will be exclusively submitted by email to pantarei@um.es. The texts will be submitted in DOC format and the images in JPEG or TIFF format, and with a minimum size of 2000 px. Images will not be integrated in the text but sent in another file and properly numbered according to their position in the text. Attached to the paper, a document will be filled out and sent where the author's data will be specified following the model available on the website.

The sixth edition of the Manual of the American Psychological Association will be taken into account for the writing of the papers. The length of the papers must not exceed 30 pages. Typography will be Arial 11 , with simple line spacing and no space between paragraphs. The text must be justified on both margins without indentation in the first paragraphs. Margins size will be $2.50 \mathrm{~cm}$. Where it could be necessary the incorporation of notes, they will be at the bottom of the page, consecutively numbered with typography Arial 10, simple line spacing and justified on both margins.

More detailed information is available on the website: http://www.um.es/cepoat/pantarei.

\section{Examination and assessment process}

The Journal will submit the papers to a first examination once received. If the paper follows the presentation guidelines, the subject agrees with the editorial line of this journal, and possess the scientific quality required, it will be sent to the advisory council for a first assessment. If not, the documents which clearly fail to complete the editorial line may be rejected straightaway in this first step.

The Advisory Council will indicate the originality, relevance, structure, writing, bibliography, etc. of the text to the journal; for this purpose, two outside experts will be designated to review the papers; these experts can be (or not) part of this Advisory Council. The selection of the experts will adjust to the subject and methodological characteristics of the paper. Name and affiliation of the author will be eliminated from the text for its review, in this way experts will act anonymously and confidentially.

The experts will fill out an assessment report which will focus on aspects such as formal characteristics, originality and novelty of the papers, relevance and results of the proposal, methodological quality and scientific validity.

Once the process is finished, the acceptance or not of the papers and its publication in the corresponding edition will be decided, as well as the modifications that may be done for its final publication. This notification will be sent by email within 6 months maximum. 


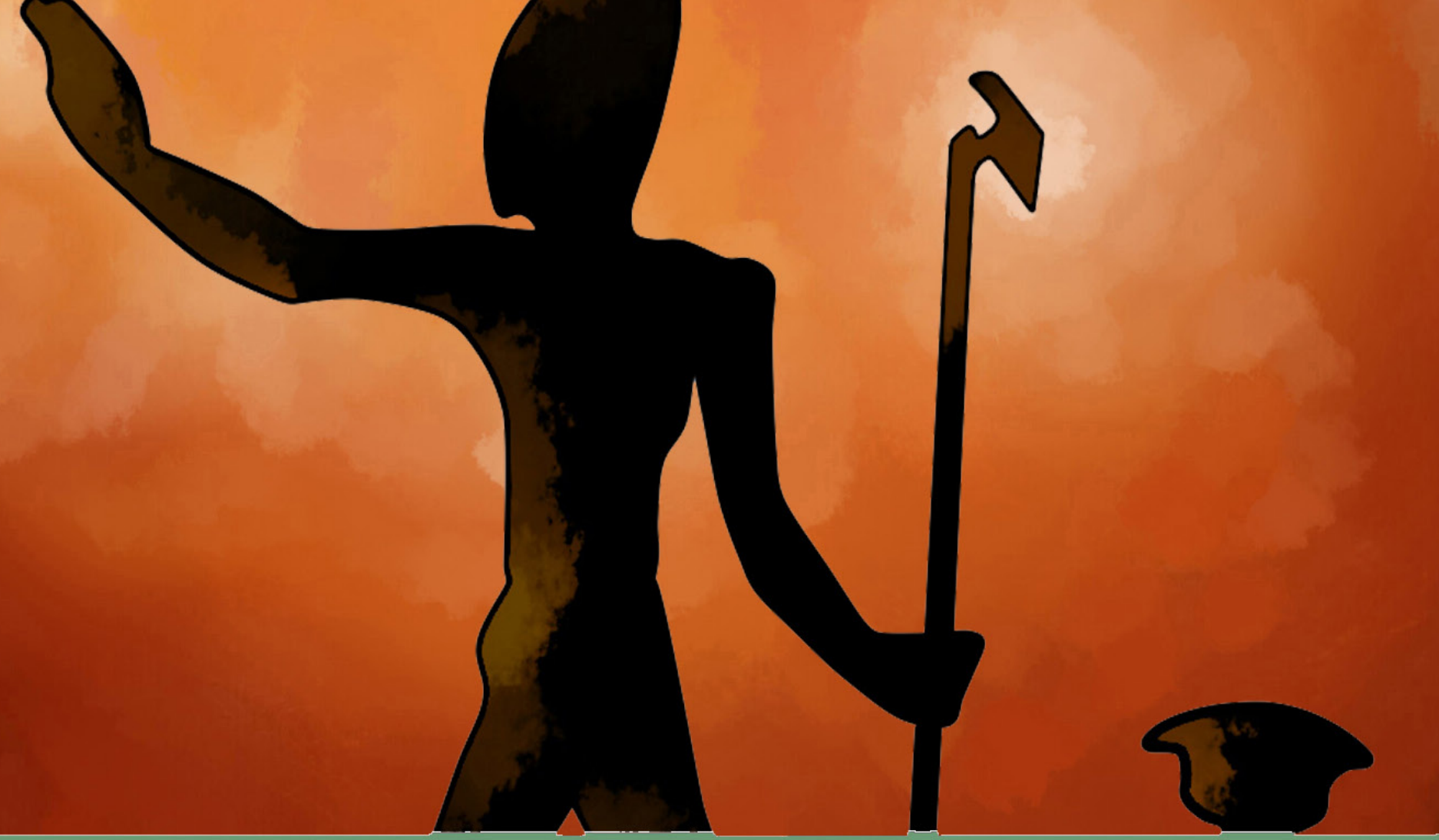

\section{cepot}

UNIVERSIDADD DE MURCIA

centro de estudios del

próximo oriente y la

antigüedad tardía 